\title{
An avant-garde collection inspired by the global water crisis: recycling waste to aesthetic garments
}

\begin{abstract}
The purpose of the chapter was to develop an avant-garde clothing collection of dresses inspired by the global water crisis, the pollution emitted by water containers, and a fear of water espoused by natural disasters like tsunamis. This chapter was initiated to express the potential value of recyclable water-related materials such as polyethylene terephthalate (PET), high-density polyethylene (HDPE), and plastic drinking straws. Avant-garde clothing collection was developed from mainly reusable plastic materials, such as plastic water bottles, drinking straws, fishing wire, light-emitting diode (LED) and fabric with a solar charging system. A theoretical conceptual framework Functional, Expressive, and Aesthetic (FEA) Consumer Need Model was adopted as ground theory to assess the garments and ground the chapter in theory.1 The FEA Consumer Need Model was also used to analyze the design collection. The avant-garde collection developed will contribute to consumers' awareness of issues related to the global water crisis while providing examples of how fashion designers and the fashion industry professionals more generally can express and create beautiful and aesthetic clothing with discarded materials or non-apparel materials. There is no existing guide on how to use unconventional materials. This chapter offers a practical guide to how to manipulate non-fabric materials into beautiful, wearable, investible art. Future research could explore other environmental issues through fashion collections using materials, such as rubber, paper, water bottle cap, plastic bags, and so on.
\end{abstract}

Keywords: aesthetics, avant-garde, dress, environmental design, fashion, led, product development, recycling, sustainability
Volume 4 Issue I - 2018

Eunju Kim, Jongeun Kim

Department of Family and Consumer Sciences, California State University, USA

Correspondence: Eunju Kim, Department of Family and Consumer Sciences, California State University, Northridge, I8I I I Nordhoff St, Northridge, CA 91330, USA, Tel 213500 0794, Email eunju.kim.594@my.csun.edu

Received: January 30, 2018 | Published: February 21, 2018
Abbreviations: PET, polyethylene terephthalate; HDPE, high-density polyethylene; LED, light-emitting diode; FEA, functional, expressive, and aesthetic; EPA, environmental protection agency; CDOC, california department of conservation; GPS, global positioning systems

\section{Introduction}

Environmental problems are quickly becoming as one of the most significant issues on the planet since the 1990s. ${ }^{2}$ As the environmental movements started 1960s, the Environmental Protection Agency (EPA) was established in the 1970s, as was the United Nations Conference on Human Environment. ${ }^{3,4}$ A U.S. government report indicates that almost 251 million tons of garbage was produced, and from that only about 87 million tons of waste materials can be recycled in 2012 in the United States. ${ }^{5}$ Environmental pollution is no longer a problem solely for certain groups of people and nations. ${ }^{6}$

The California Department of Conservation (CDOC) issued a statement that more than a billion plastic water bottles are thrown in the trash each year in California.7 American used 50 plastic water bottles in $2007 .{ }^{8}$ Unfortunately, $77 \%$ of Americans did not recycle plastic water bottles, leading to a recycling rate of $23 \%$ in the United States each year. Every year, 38billion plastic water bottles worth one billion dollars were consumed. In Europe, the recycling rate was about $50 \%$ higher than the US, and about 60 million plastic water bottles were recycled in $2015 .{ }^{9}$

The apparel and textile industry is a major contributor to both environmental pollution and environmental conservation, fighting pollution by using such by-products as plastic fibers from recycled clear plastic water bottles made of polyethylene terephthalate. ${ }^{10}$ Fashion industries have been concentrating on decreasing their environmental pollution for more sustainable practices. ${ }^{2}$ However, the field of fashion design has been lagging in a survey of eco-friendly design goods compared with architecture and industrial design. ${ }^{11}$ Yet, people in the fashion industry including politicians and consumers became aware of the environmental issues concerning animal and human rights in the 1980s. ${ }^{4}$ Fashion designers, such as Issey Miyake and Katherine Hamnett, have shown interest in environmental issues by focusing on them within the fashion industry. The development of eco-fashion has enabled the purchaser or user to be fashionable while staying aware of the pollution caused by the fashion industry. ${ }^{4}$ Eco-fashion became a social statement in the realm of environmental movements, but this word was invented for mostly apparel scholars and marketing purposes. ${ }^{11}$ Consequently, one way to announcing the water bottles usability to public could be developing aesthetic dress collections and exhibit the collection to public by using discarded water-related products.

The word avant-garde (from the French for "advance guard") originated from France in a "military sense" and it was used literally in English during the 15th-18th century. ${ }^{12}$ After 1920, the word was used as an artistic concept describing people or practices not accepted in the current moment that would become standard practice later. ${ }^{13}$ However, after the 1980s, artists and aesthetic ideas of an avant-garde theme slowly discontinued in Europe, but became more popular in the western world. ${ }^{14}$ The meaning of avant-garde is one unique phenomenon in art, which is difficult to comprehend; at the same time, people's preconceptions make it difficult to accept them as a norm..$^{15}$ Designers such as Howard Becker have made contributions 
to the sociology of art, finding their inspiration primarily from objects in their everyday life for their artwork. ${ }^{15,16}$ Avant-garde fashion magazines inspire people to point toward a new fashion taste in order to show the readers a new method. ${ }^{16}$ Lifestyles are signified as material goods become signifiers of that lifestyle. ${ }^{16}$ Aesthetic avant-garde artists play an important role in expressing and creating awareness social issues especially in the era of globalization. Also, avant-garde principles are firmly grounded in environmental destruction, cultural democracy, and global community of residents. ${ }^{14}$

\section{Statement of the problem}

This chapter began as a way to inspire fashion industry professionals and eventually the greater public to incorporate sustainable materials and methods into everyday life. Because the use of water bottles is prevalent, focusing on water bottles as the main medium serves to inspire and educate people to be creative with materials as well as raise awareness for environmental sustainability. The problem addressed by the current study focused on the detrimental factors caused by the increased use of plastic water bottles worldwide, such as the severity of environmental pollution, threats to various ecosystems, and the resulting financial loss. At the same time, many countries are facing a severe water crisis. In addition, there is an increasing need for sustainable, technical and futuristic apparel items in the fashion industry. The development of avant-garde collection has led to a reintroduction of environmental concerns and a push to promote awareness of the environmental issues of consumers. In response to the current trend in awareness and interest, consumers have been lead to think about the effects of recycling items such as plastic water bottles and how we control our environment with a limited amount of resources. Many events, art works, articles, and public writings have been focused on pollution and environmental crisis. However, there are limited collections and art works that address how this pollution could transform into aesthetically pleasing dresses. Furthermore, there is no study to show how to transfer trash (e.g. recyclable plastic bottles) into wearable art. This chapter addresses a gap in the knowledge between eco-fashion practitioners and more traditional avant-garde designers in that while eco-fashion is sustainable, it does not always incorporate innovative design. Conversely, avant-garde design relies on many hours of labor and materials but does not respond necessarily to environmental issues such as the global water crisis. This chapter situates itself between the two to further the sustainable practices of avant-garde design and the innovation and aesthetics of eco-fashion. Finally, this chapter offers a practical guide to how to manipulate nonfabric materials into beautiful, wearable, investible art. ${ }^{17}$

\section{Purpose}

The purpose of this thesis chapter was to develop an avant-garde clothing collection using water-related waste materials in order to express the reusability of discarded water bottles, even further more valued aesthetic dresses. The collection explored a new way for consumers to educate themselves about pollution created by waterrelated waste materials and how to reuse this waste to upcycle to make dresses. It also provides examples to fashion designers and the fashion industry a way to create avant-garde clothing collection by using discarded materials or non-apparel materials. By sending a message to the public, this study tries to demonstrate that there is a novel way to save the planet by upcycle plastic water bottles. The inspiration for this chapter was influenced by the global water crisis, focusing the importance of pure water, water and plastic pollution, and fear of water caused by natural disasters like tsunamis ${ }^{1} .^{18}$ Fear of tsunamis and images of tsunamis were expressed through dress figures such as flow of dress (skirt). In addition, this study has explored ways to transfer used high-density polyethylene (HDPE) and polyethylene terephthalate (PET) recyclable bottles into a dress with detailed steps. The Functionality, Expressiveness, and Aesthetics (FEA) Consumer Need Model was adopted as the theoretical framework, served to guide the design and an analytical framework of the final collection. A high-quality artistic collection created using recycled garbage will hopefully encourage consumers, apparel designers, and future generations that recycling plastic water bottles is important and achievable. The behavior of consumers will be enhanced by the synergy of beauty and lead to a more valuable social contribution via increased recycling use of discarded materials and reuse more generally.

\section{Definitions}

Avant-garde: Originated from a French military term that was translated literally as "advance guards," now it is used to describe innovative artists and is used traditionally to express an original artistic style with significant technique. ${ }^{13}$ It is frequently used in works that are experimental, nontraditional, or extreme in clothing design or other works of art, and are described as "new," "cutting edge," or "ahead-of-its time". ${ }^{19}$

LED: Light Emitting Diodes (LEDs) are based on traffic signals, conserving millions of kilowatt hours and providing long-lasting, energy-efficient and less maintenance light derivation. LEDs have different light colors and technologies from fluorescent lamps to incandescent bulbs. $^{20}$

Recyclable waste: Recyclable waste means collecting discarded materials, separating and cleaning the material and then re-forming it into a new product for extended use. Recycling waste saves raw materials and reduces energy and resource consumption while producing consumables. ${ }^{21}$

Eco-art: The eco-artistic modern movement was started by an artist who was interested in the eco-friendly production of art, which is also called ecological art, and focuses heavily on local and global environmental issues. The word "eco" has a Greek origin and means "home" 22

Aesthetic: The word, aesthetics comes from the Greek word "sensory impressions" and can be used to describe all "things perceptible to the sense". By this definition, anything that can be observed can be jud$\mathrm{ged} /$ noted/ seen/ viewed based on aesthetics. Since the late Eighteenth century, aesthetics has come to mean not only sensory perception but also "perception of the beautiful". ${ }^{23}$

Recycling: Collecting, storing, transporting, separating and reusing materials that can be used to produce a new product out of old materials. $^{24}$

Sustainability: A practice or way of living that encourages quality of life while protecting natural living environments and resources so various ecosystems are able to adapt and diversify in peace also includes economic and human components. Sustainability is a lifestyle which espouses the need to provide the current generation with enough to live comfortable while decreasing environmental damage that will negatively impact the future generations..$^{25,26}$

${ }^{1}$ Tsunami: Tsunami, also called seismic waves, earthquake waves, or tidal waves, are a series of massive waves generated by underwater disturbances, such as volcanic eruptions, earthquakes, meteorites, or landslides. ${ }^{17}$ 


\section{Review of literature}

This chapter developed an avant-garde clothing collection informed by the theme of the global water crisis and plastic pollution caused by disposable water bottles. In this chapter, the global water crisis, the effects of plastic water bottles, environmental awareness and understanding of recyclable materials, recycling plastic trash in fashion, recycling plastic trash in art, and LED and solar fashion related research have been reviewed. Then, a theoretical conceptual framework Functional, Expressive, and Aesthetic (FEA) Consumer Need Model is examined.

\section{Global water crisis}

If water supply is less than demand, a water crisis will occur, causing a serious problem. ${ }^{27}$ Water is essential for all humans, animals, and plants on Earth to live. However, available fresh water makes up only one percent of the world's total water supply. The United Nations claims that thirty-one countries face water shortages, and over one billion people do not have access to clean drinking water. By 2025 , the world population is expected to grow by 2.6billion people, with two-thirds living with serious water shortages and one-third facing absolute lack of water. The world's thirst will be one of the most important resource problems of the 21 st century, according to the UN Environment Program, the World Bank and World Resources, a publication of the World Bank and World Resources Institute. ${ }^{28}$

\section{The effects of plastic water bottles}

Environmental impacts: Polyethylene terephthalate (PET) is made from crude oil. ${ }^{9} 17$ million barrels of oil were utilized to produce plastic water bottles, with a waste discharge of 24billion plastic bottles annually in the United States. To produce and transport one plastic water bottle, one liter of fossil fuel was used, and 1.2lb of greenhouse gasses was emitted. Over 800,000 metric tons of contaminants were released into the atmosphere during the manufacture of plastic water bottles, and 6.74gallons of water are utilized to produce and transport a one liter bottle. There were 46,000pieces of plastic per square mile, and $90 \%$ of all waste on the surface of the sea was plastic. However, only one in six plastic water bottles were recycled properly. ${ }^{29}$

Health impacts for humans: PET is comprised of chemicals that break down hormones, interfering with reproduction and estrogen and leading to breast cancer, birth defects, premature birth, decreased fertility in women and male breast enlargement. ${ }^{29}$

Animal impacts. In 2013, one hundred thousand marine mammals and one million ocean birds died from ingesting plastic water bottles. ${ }^{29}$ Plastic bottles caused sea water pollution, threatening marine creatures, and ocean birds causing major ecological problems. According to the Ocean Conservatory, more than 46,000 pieces of plastic float on every square mile of the sea and were eaten by marine birds and creatures. ${ }^{9}$

Financial impacts. The annual value of the bottled water industry worldwide was \$58billion a year, and \$16billion was spent on bottled water in the United States. Every second, 1,500plastic water bottles were purchased in the United States alone. ${ }^{29}$

\section{Environmental awareness and understanding of recy- clable materials}

Global awareness and performance about environmental problems have appeared since 1973 due to the energy crisis. This major issue of environmental pollution brought about sustainable green design and eco-friendly goods through environmental resources. ${ }^{3,30,4}$ The fashion market, mass media, education, and end-users have been conscious on ecological and environmental movement in the last 15years. From an environmental campaign, eco-fashion has attracted and recreated concepts of fashion marketing and journalism. ${ }^{11}$ Therefore, sustainable art and chapters were transformed into a portion of a worldwide campaign of sustainability to show possible strategies of sustainable development; predominantly, recycling products actually mean down-cycling, which results in a lower quality of the stuff after some time. ${ }^{11,31,32}$ The United States Environmental Protection Agency (EPA) indicated that an average of daily waste of Americans accrue 4.38pounds along with 1.51 pounds recycled. ${ }^{5}$

The EPA has announced that recycling and waste compositing has kept out about 86.6 million waste materials in 2012, as this showed a notable comparison in 1980 of 15 million tons. ${ }^{5}$ Figure 1 shows the rate of materials and waste. In fact, a major part of waste is paper materials accumulated up to $27.4 \%$ and food waste, yard trimming, and plastics add up to about $13 \%$. Moreover, metal, rubber, and textile follow about eight percent. To end, wood and glass make up an average five percent in Figure 1.5

Hence, The EPA promotes applications that decrease the amount of waste through recycling, compositing, and waste prevention. ${ }^{5}$ Global awareness and action on environmental problems considered the major issue of environmental pollution, which have brought about sustainable green design and eco-friendly goods through environmental resources. ${ }^{3,30,4}$ Typically, there are two types of recycling, upcycling and downcycling. ${ }^{32,11}$ Upcycling is widespread amongst art designers in every area of the globe.$^{31}$ Generally, recycling is downcycling that downgrades a quality of a substance. ${ }^{11}$ In contrast, upcycling elevates value through customizing materials and art. ${ }^{31}$ In addition, upcycling is characterized with a "design and make" ability that results in conventional products as well as recreated products with a higher value in the end. ${ }^{31}$

Major components are paper, plastic, rubber, textile, and food scraps. This paper discusses upcycling as one of the ways to recycle products as a sustainable chapter and how to incorporate it to real-life products and art products. People may have questions about upcycled goods worth against previous waste. ${ }^{32}$ Also, people may wonder how they can make avant-garde designed clothing using waste.

\section{Recycling plastic trash in fashion}

Most plastic water bottles are sent to the garbage, and are ultimately dumped into waterways and landfills, where they will take hundreds of years to break down. ${ }^{9}$ Unifi, a global textile company located in Greensboro, North Carolina, extrudes and melts the pellets to emit reusable polyester yarn, $100 \%$ Repreve, all made from plastic bottles. The brand companies that use this yarn include Nike, Patagonia, Levi's, Adidas, Ford and The North Face. Furthermore, 400,000 US college students graduated in 2016 wearing 100\% Repreve graduation gowns, made by Oak Hall Cap \& Gown. Jay Hertwig, vice president of global branding for Unifi, said it could make one gown with 27 used plastic water bottles. These days, more than 1,250schools, including Yale, Brown University, Michigan, Notre Dame and the University of North Carolina at Chapel Hill, use graduation gowns based on $100 \%$ Repreve yarns. ${ }^{33}$

\section{Recycling plastic trash in art}

Plastic pollution is increased proportionately as the world 
population increases..$^{34}$ The Defense Council of Natural Resources estimate that plastic pollution prevention costs around \$428million a year for 95 communities in the state of California. ${ }^{35}$ Not only that, the amount of plastic consumption was about 260 million tons worldwide in 2012 but rose up to 297.5 million tons in $2015 .{ }^{34}$ On top of this, to reduce the environmental pollution caused by plastic, there are several artists who made art works using plastic water bottles.

In a flood of plastic consumption, converting waste into a recreated art work will be a valuable up-cycling. For example, Maryellen Croteau, Jane Parkins and Zac Freeman are portrait artists who transform found materials into new artworks in Images 1-3. Images 4-6 show ways to use recycled plastic water bottles in real life. The artistic works of plastic bottles use a sculpture technique by cutting plastic bottles into flower shapes, as in the flowerpots in Image $4^{2}$. Angelo Fernandes and Eline Pellinkhof are artists of planting and gardening, using plastic bottles to display in homes and stores (Image 5) ${ }^{3}$. Other creative artworks to use plastic water bottles are seen in Rod Pujante's Flower Art and Michelle Brand (Image 6) ${ }^{4}$. They developed the use of cutting and heating techniques to make decorations with waste plastic bottles. These plastic waste materials breathe in the art of life, therefore, reborn into beautiful artwork. Definitely, these artworks will be rewarding for donors who donated waste to be recycled but now turned into eco-art for the public to enjoy.

\section{LED and solar in fashion}

Lately, LED and solar solutions have been made into wearable technology in the form of clothing and shoes in the fashion industry. ${ }^{36}$ Indeed, fashion designers are using LEDs and solar panels in their products for sale in retail stores and online as well. ${ }^{37}$ Levi's Fashion Futures and Sony Global Company have developed a scenario for 2025 based on problems, such as water and material shortages and climate change, which actually reduces water usage during production. ${ }^{38}$ Other Eco-fashion designers are developing fashion items incorporating the light-emitting diode (LED) into their clothing, accessories, and shoes (Images 7$)^{5}$ (Image 8$)^{6}$, and are also developing solar clothing using flexible solar cells (Image 9$)^{7}$ (Image 10) ${ }^{8}$.

\footnotetext{
${ }^{2}$ Acknowledge the picture image from https:/www.pinterest.com/ $\operatorname{pin} / 427138345887413554 /$,

Acknowledge the picture image from https://www.pinterest.com/ $\operatorname{pin} / 203225001910234576 /$,
}

Acknowledge the picture image from http://beautifulpeopleliveart.com/ jewellery-designer-fabiana-gadano/,

Acknowledge the picture image from http:/www.inspirationrealisation com/2012/11/do-inspire-yourself-18.html, Acknowledge the picture image from http://klimt02.net/jewellers/fabiana-gadano, Acknowledge the picture image from https://ifitshipitshere.blogspot.com/2010/09/stunning-bowlsmade-from-recycled.html

${ }^{3}$ Acknowledge the picture image from https://www.pinterest.com/ pin/543598617500492960/, Acknowledge the picture image from http:// elinepellinkhof.blogspot.fr/2011/09/woonbeurs-part-2.html

${ }^{4}$ Acknowledge the picture image from http://www.staroftheeast.us/2015/07/9great-ways-to-recycle-plastic-bottles.html

${ }^{5}$ Acknowledge the picture image from https://www.pinterest.com pin/486459197222958029/, Acknowledge the picture image from http://www. trendhunter.com/slideshow/flashy-led-fashion

${ }^{6}$ Acknowledge the picture image from https://afromonk.com/2010/07/16 hussein-chalayan-moritz-waldemeyer-led-fashion/

${ }^{7}$ Acknowledge the picture image from http://tek-think.com/2015/08/22/ flexible-led-technology-may-complement-flexible-solar-thin-film-clothing/

${ }^{8}$ Acknowledge the picture image from c-phone-charger-you-wear/

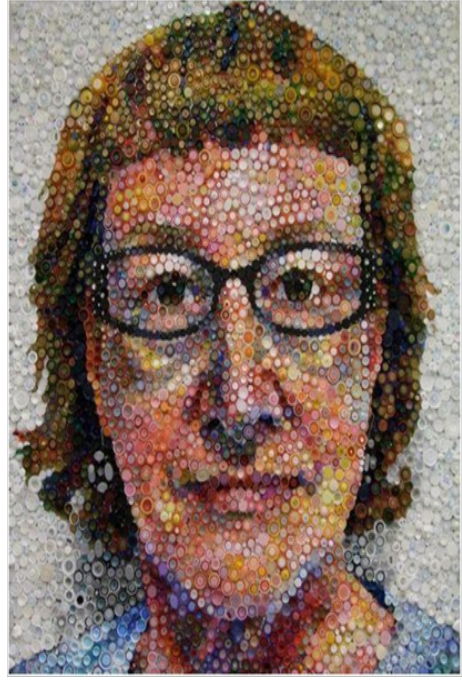

Image I A large scale self-portrait, 728x546 By Maryellen Croteau (C.

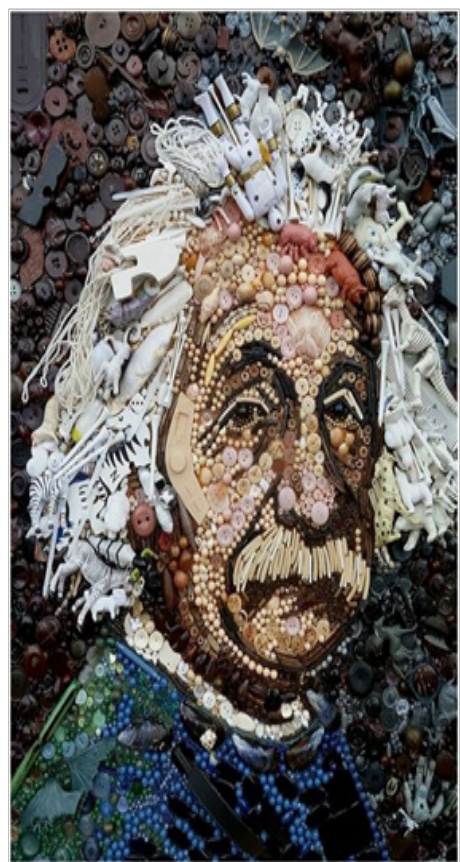

Image 2 Einstein, Collage from found materials, $201 \mathrm{I}, 70 \mathrm{~cm} \times 50 \mathrm{~cm}$ by Jane Parkins (C).
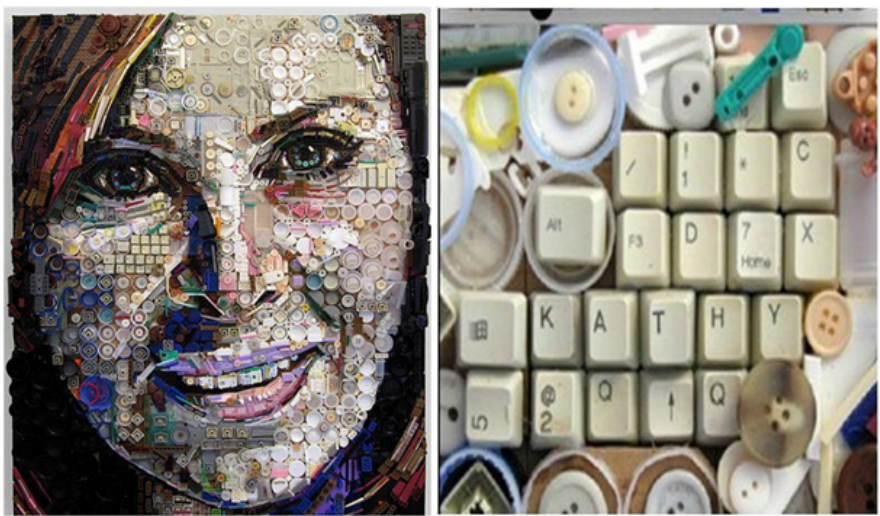

Image $\mathbf{3}$ The junk portraits of Zac Freeman art. 

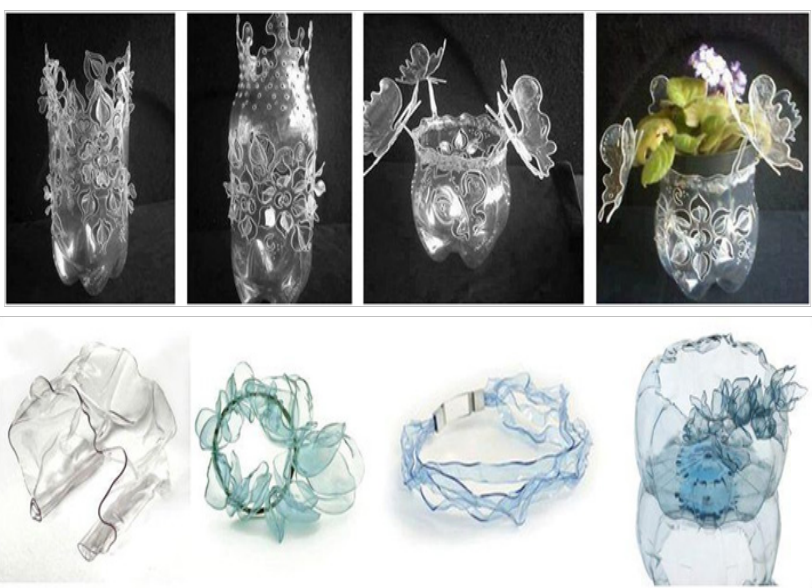

Image 4 Plastic beauty and crumpled plastic cuff bracelet.

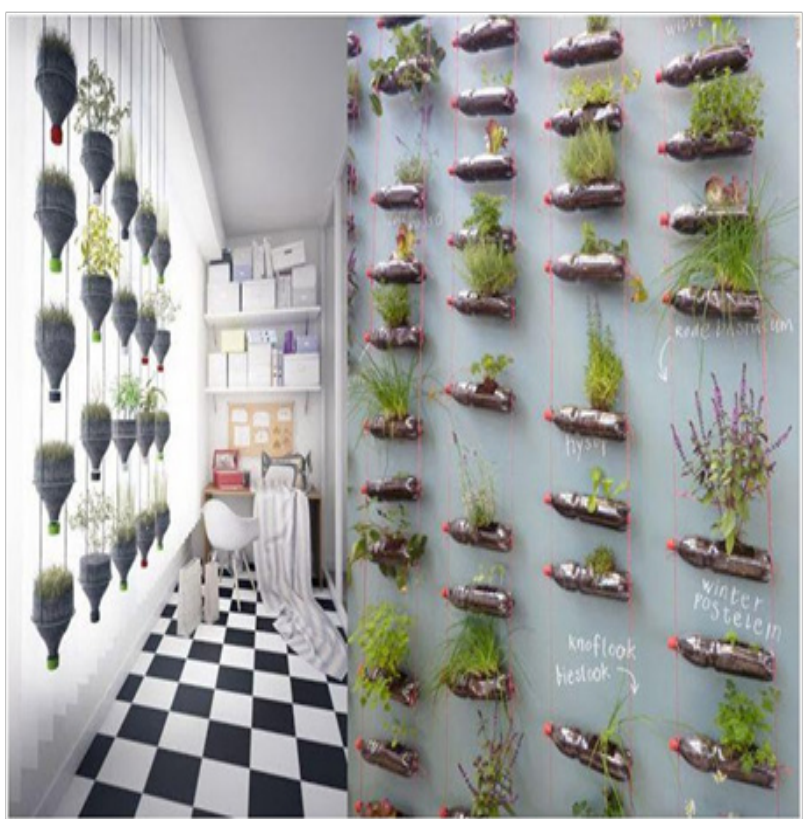

Image 5 Angelo Fernandes and Eline Pellinkhof.

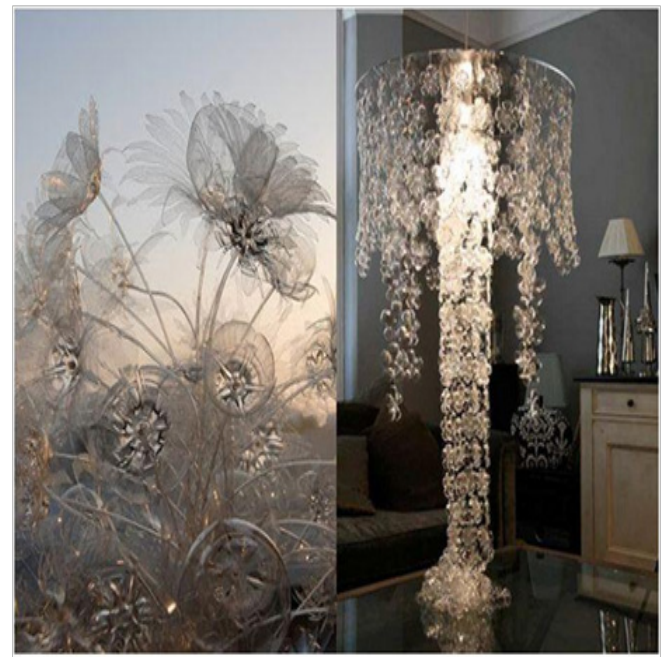

Image 6 Rod Pujante's flower art and Michelle Brand.
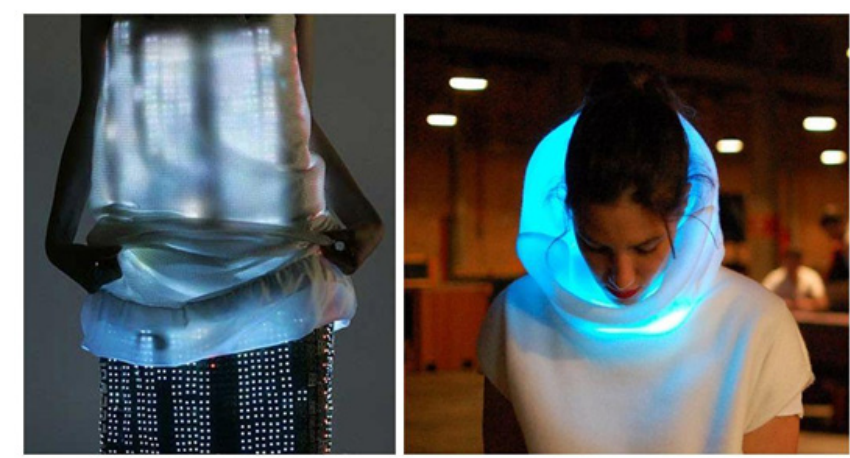

Image 7 LED fashion.
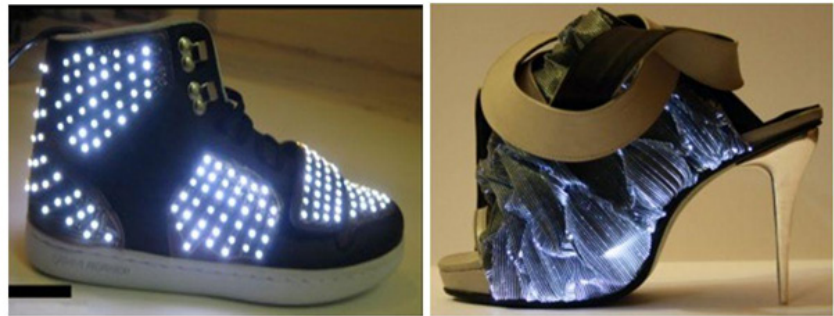

Image 8 LED sneakers and heels.

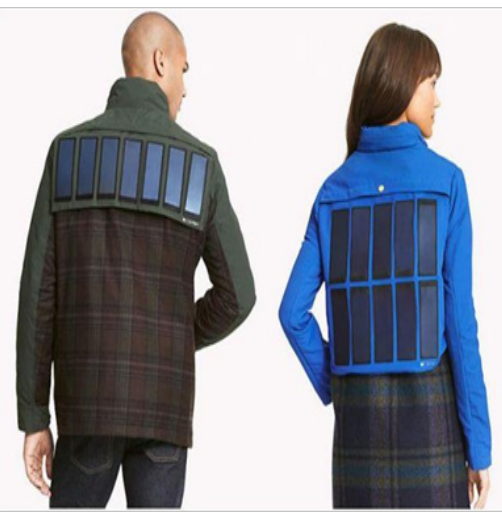

Image 9 Solar powered design from Tommy Hilifiger.

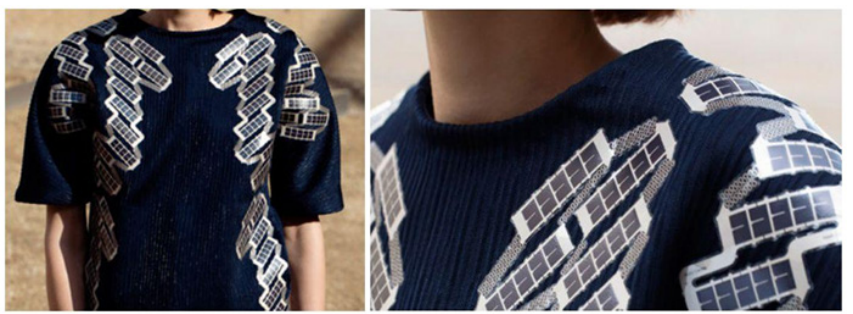

Image I 0 Solar shirt design from Pauline van Dongen.

Researchers at National Chiao Tung University, Taiwan have created white LEDs that are very flexible and efficient with wearable displays, such as flexible and curved TV screens. ${ }^{39}$ In line with this trend, various companies are now developing designs and ideas for using LED clothing to move into other fashion industry markets. This has allowed the consumer to wear technological advanced fashion items with attached LEDs, such as T-shirts, dresses, jackets and shoes. Katy Perry was a one of the first fashionistas to wear a brightly shining LED dress, and she also wore a Cute Circuit gown with brightly colored rope lights at the 2010 Met Gala. ${ }^{37}$ 
LED apparel that can send literal messages with glittering lights and motion detector, and technology that can display characters in clothes is emerging. This technology allows a customer to display a tweet with a specific hashtag, and can be lit or change color as the wearer desires. ${ }^{37} \mathrm{In}$ an interview with $\mathrm{CNN}$ the company representative for Electric Styles, one of the fashion technology companies, said that there is a change happening in the younger generation with a cultural shift in how they express their personality in their fashion. ${ }^{37}$ In addition, LED technology and solar fashion are designed to protect customers' safety when they are riding bicycles or walking, as a way for pedestrians and drivers to notice them when traveling at night. ${ }^{40}$

Dutch designer Pauline van Dongen unveiled the "Solar Shirt" in 2015 in Austin, and the Wearable Solar line was developed jointly with the Holland Holst Center in Holland. ${ }^{36}$ The Solar Shirt is showed to produce electricity using 120 thin-film solar modules integrated into the fabric of the garment (Image 10). In sunny weather, a solar shirt produces about one watt of electricity, so you can charge your iPhone within a few hours. ${ }^{36}$ This Van Dongen costume can also be used with other USB-compatible portable devices such as Global Positioning Systems (GPS), cameras, MP3 players, and can be stored in the battery pack of the shirt for later use. Though previous attempts to combine solar heat with fashion led to disposable auto-couture designs, Holt Center's washable interconnect technology, not to mention stretching, have made the process altogether smoother. ${ }^{36}$

Jayan Thomas, an associate professor at the University of Central Florida's Nano Science Technology Center, has developed filaments that can be easily woven into fabrics, which can then be transformed into clothing that also serves as a rechargeable solar cell. ${ }^{41}$ This wearable smart apparel was also announced in 2016 by Nature Communications, which not only makes it easier for ordinary customers to use solar clothing, but also for the military and soldiers who need to carry a 30-pound battery. The filament fabric is said to be able to charge smart phones, work with extra battery sets, or power personal portable devices. ${ }^{41}$

\section{Theoretical framework}

This chapter has adopted the theoretical framework of the Functional, Expressive, and Aesthetic (FEA) Consumer Needs Model to analyze the collection created by Lamb and Kallal in $1992^{1}$ (Figure 2 ). The model consists of three parts: functional, expressive, and aesthetic with the target consumer as the center of a circle. Each dress utilizing a theme of environmental pollution was analyzed by applying the FEA model. The functional aspect of clothing item consists of its fit, and closure characteristics suitable for a particular idea for which the garment was made. For the fitting the body, the representative dresses used a princess line to emphasize femininity and elegance. All of the dresses were finished using hook and eye, zippers, fishing wire, crimp beads, and snap buttons, which met the element of functionality needs of dress for the FEA Consumer Needs Model. The expressive aspect of apparel consists of pursuing and expressing awareness of environmental issues. Most of the materials used were recyclable plastic such as 500-milliliter polyethylene terephthalate (PET) water bottles, recycled parts of one gallon high-density polyethylene (HDPE) water bottles, and clear plastic drinking straws. Lastly, the aesthetic aspect of a garment consists of design principles and elements, and harmonizing and balancing the body and the garment relationship. The dresses were constructed based on design elements, such as point, line, shape, form, space, color, and texture, and design principles, such as emphasis, balance, rhythm, harmony, proportion, perspective, movement, pattern, repetition, variety, and unity. Thus, aesthetic view of a garment concerns beauty for consumer's desires. ${ }^{1,2}$ The concepts for all of the dresses were filtered through cultural perspectives such as sustainability and consumer' awareness of issues related to the global water crisis. In addition, target consumers want to know how to combine sustainability and technology through fashion, which gave the fashion designers and fashion industry professionals motivation. Now, the FEA Consumer Need Model has been designated to analyze general characteristics of avant-garde garment products in this study. ${ }^{2}$

\section{Methodology}

The purpose of this chapter was to develop an avant-garde dress collection using recyclable materials. The global water crisis and environmental waste were the design inspiration for up-cycling aesthetic clothing design.

To guide costume design, as well as an analytical framework of the final collection, the Functionality, Expressiveness, and Aesthetics (FEA) Consumer Need Model was adopted as the theatrical framework. The collection formed basic structural development. Then, all garments were applied with environmental materials based on their concept designs displayed through concept sketches. Accordingly, final dresses will be shown through a photograph at the results session

\section{Procedures in general}

Assessment: Each avant-garde dress presented by up-cycling and eco-art through recyclable waste materials. Each stages of garment production followed the seven steps of development stage in Table 1: problem recognition of environmental pollution, concept theme board, concept production map, product development, final product, actual product and exhibition. The procedure to develop dresses based on the seven steps of the development stage was explained in the results chapter. The collection was developed using the concept map, color and fabric board, and design storyboard.

Table I Avant-Garde Collection Development Process

\begin{tabular}{|c|c|c|}
\hline S.No. & $\begin{array}{l}\text { Stages of } \\
\text { development }\end{array}$ & Contents \\
\hline \multirow[t]{2}{*}{ I } & $\begin{array}{l}\text { Problem } \\
\text { Recognition of } \\
\text { Environmental } \\
\text { Pollution }\end{array}$ & $\begin{array}{l}\text { Review literature and research about } \\
\text { fashion industry and social issues on } \\
\text { pollution. }\end{array}$ \\
\hline & & $\begin{array}{l}\text { Influence of waste to environmental } \\
\text { pollution, the global water crisis: } \\
\text { recycled water bottles, plastic } \\
\text { drinking straws, crystal beads, hotfix } \\
\text { stones, and fashion fabrics. } \\
\text { Up-cycling \& Eco-fashion. }\end{array}$ \\
\hline \multirow[t]{2}{*}{2} & $\begin{array}{l}\text { Concept theme } \\
\text { board }\end{array}$ & $\begin{array}{l}\text { Concept of each design with related } \\
\text { materials. }\end{array}$ \\
\hline & & $\begin{array}{l}\text { Color, fabric, material, silhouette, } \\
\text { trim, and detail of each related } \\
\text { garbage by environmental inspiration. }\end{array}$ \\
\hline \multirow[t]{2}{*}{3} & $\begin{array}{l}\text { Concept } \\
\text { Production Map }\end{array}$ & $\begin{array}{l}\text { Make concept design board for each } \\
\text { theme and recycling waste material. }\end{array}$ \\
\hline & & Rough sketches. \\
\hline
\end{tabular}


Table Continued.

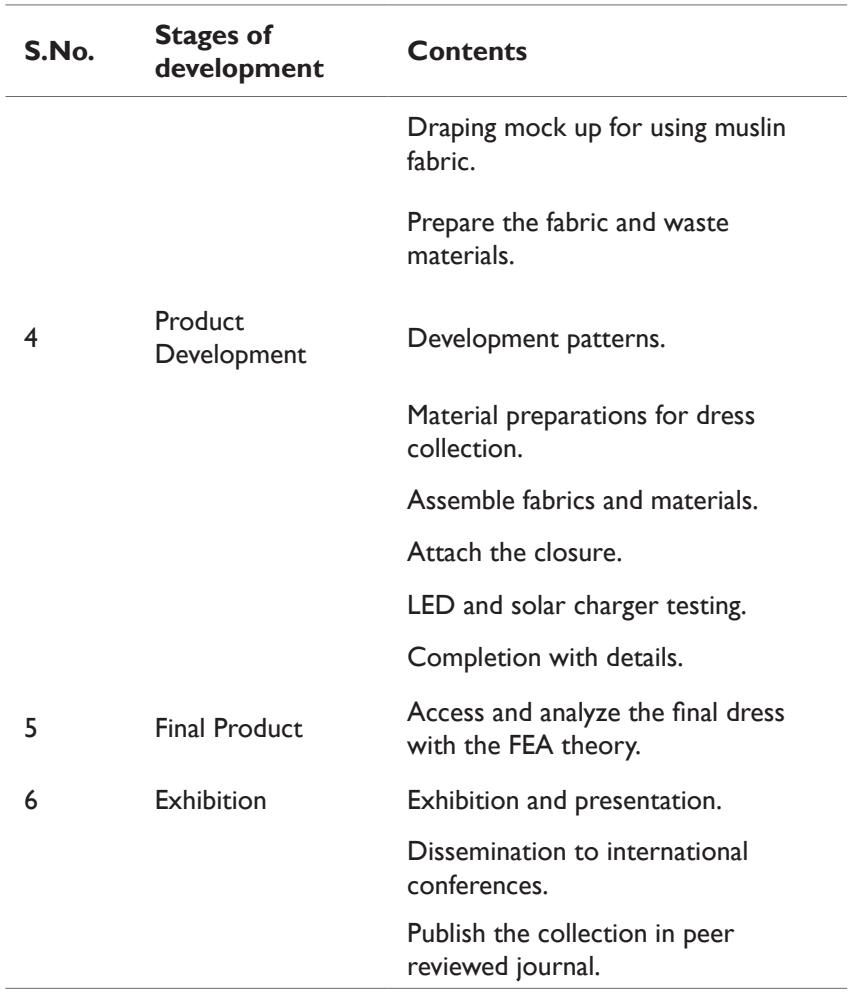

\section{Functional, expressive, and aesthetic consumer need model}

This chapter was adopted the theoretical framework of the Functional, Expressive, and Aesthetic (FEA) Consumer Need Model to analyze the collection. ${ }^{1}$ The functional aspect of design was concerned with a satisfying fit, and closure elements were adopted for functional analysis. Then the princess line cut was used to satisfy fit elements. Snap buttons and zippers were used as closer element analysis for donning and doffing. The expressive aspect of the garment was trying to communicate the idea of awareness of the global water crisis and upcycling of water-related waste could be transformed to beauty. The values of the dresses were expressed by using recyclable materials, such as plastic water bottles, plastic drinking straws, fishing wire, and polyethylene terephthalate panels for expressive analysis. Lastly, the aesthetic aspects of the design registered its own beauty by using design principles and art elements through the body and garment relationship. The dresses used several styles of crystal beads, hotfix stones, gold leaf gilding, and fashion fabric as prestigious decorations to explore aesthetic elements. The length and weight of the dresses have been considered and analyzed in order to look more beautiful and match the balance of the dresses.

\section{Results and discussion}

\section{Development of collection}

Product development: This collection developed through the inspiration of the global water crisis and environmental contamination, such as water shortage, water security, water pollution, plastic pollution, and the calamity of the tsunami crisis in the oceans. The related inspiration from the global water crisis pictures are as follows (Image 11)

${ }^{9}$ Acknowledge the picture image from https:/www.pinterest.com/ pin/354025220691812600/, Acknowledge the picture image from https://www.
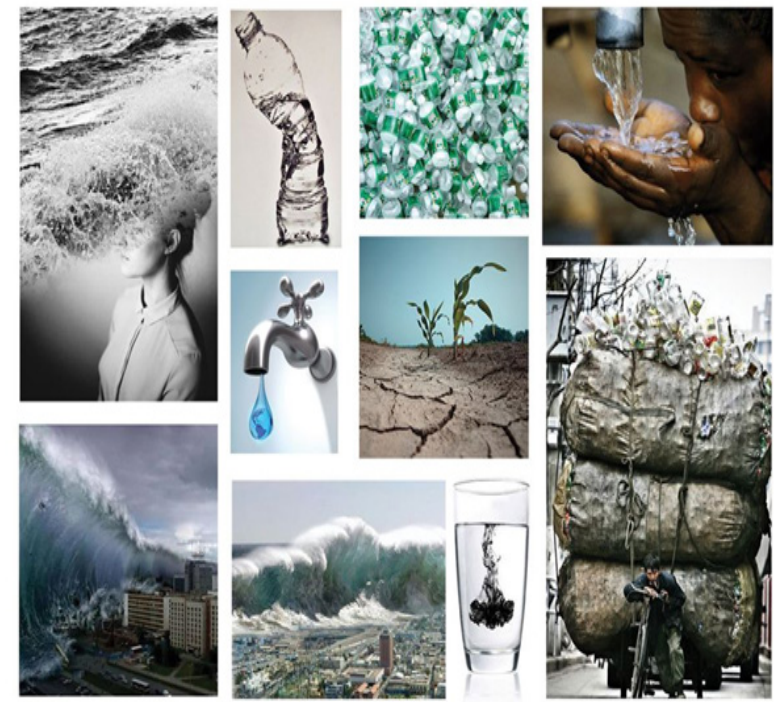

Image I I Problem of the global water crisis and issue identification.

The concept theme board of this collection expressed images of the global water crisis and environmental problems, suffering of human beings due to these issues, and expresses human nature of wishing for a better, beautiful life (Image 12) ${ }^{10}$.

pinterest.com/pin/354025220691815161/, Acknowledge the picture image from https://www.pinterest.com/pin/354025220691814812/, Acknowledge the picture image from

http://environment.nationalgeographic.com/environment photos/freshwater/\#/ethiopia-tapwater_ $150 \_600 \mathrm{x}$ 450.jpg, Acknowledge the picture image from

http://www.infobarrel.com/Media/Save_water,_save_the_world, Acknowledge the picture image from https://www.pinterest.com/ pin/354025220691814866/, Acknow-ledge the picture image from http://indulgy.com/post/ul9sudemN1/tsunami-tsunami-scary-spookyhaunt, Acknowledge the picture image from https:/www.pinterest.com/ $\mathrm{pin} / 354025220691811829 /$, Acknowledge the picture image from https://www. pinterest.com/pin/354025220691814810/, Acknowledge the picture image from http://chihira-masamichi.tumblr.com/post/99171737182/wdbrkbrmghmarminann

${ }^{10}$ Acknowledge the picture image from https:/www.pinterest.com/ pin/354025220691812678/, Acknowledge the picture image from https:// www.pinterest.com/pin/354025220691930622/, Acknowledge the picture image from https:/www.pinterest.com /pin/354025220691930638/, Acknowledge the picture image from https:/www.pinterest.com/ pin/354025220691814952/, Acknowledge the picture image from https://www. pinterest.com/pin/354025220692085239/, Acknowledge the picture image

from https://www.pinterest.com/pin/354025220694665241/, Acknowledge the picture image from https://www.pinterest.com/pin/354025220692316151/, Acknowledge the picture image from https:/www.pinterest.com/ pin/354025220691813258/, Acknowledge the picture image from https://

www.pinterest.com/pin/354025220691811924/, Acknowledge the picture image from https:/www.pinterest.com/pin/354025220691814895/, Acknowledge the picture image from https:/www.pinterest.com/ pin/354025220694673012/, Acknowledge the picture image from https://www.

pinterest.com/pin/354025220692316304/, Acknowledge the picture image from https://500px.com/photo/2736114/untitled-by-canon-rumors?from=fav orites\%252Fkimofkims, Acknowledge the picture image from https://www. pinterest.com/pin/354025220691830434/, Acknowledge the picture image from https://www.pinterest.com/pin/354025220692227003/, Acknowledge the picture image from https:/www.pinterest.com/pin/354025220692052394/, Acknowledge the picture image from https:/www.pinterest.com/ 


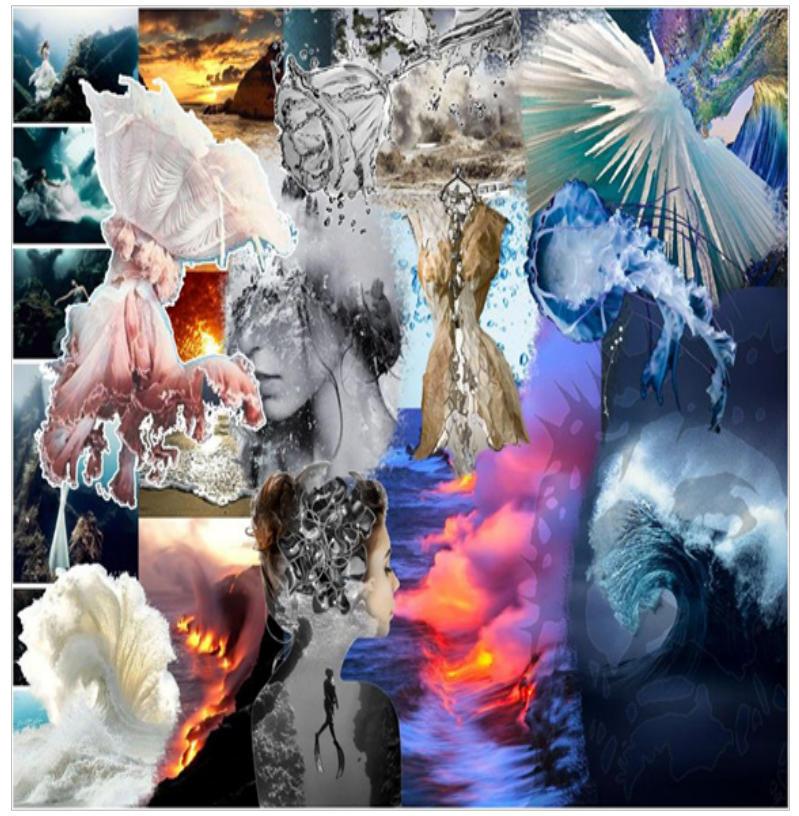

Image 12 Collection concept theme board.

The collection have five main colors: clear, white, blue, nude, and gold for each dress while the point color is shinny prismatic radiance crystal for its use of accentuate color. Then, the main materials consisted of plastic water bottles, plastic straws, polyethylene terephthalate (PETG), high-density polyethylene (HDPE), fishing wire, crystal beads, crimp beads, hotfix stones, gilding gold leaf, and light-emitting diode (LED) lights (Image 13). Some unique fabrics such as mesh, tulle, and lace were used to assist the mixing and matching with the recycled waste materials. Also, dresses have snap buttons, hotfix stones, hook and eyes and zippers for the closure of garments to increase functional aspects of design. The clear, white, and blue colors symbolized clean, transparent water, and the gold and nude colors represented that water is the purest gold. Here in Image $14^{11}$ shows the collection's concept through color story.

pin/354025220692105671/, Acknowledge the picture image from https:// www.pinterest.com/pin/354025220692226905/, Acknowledge the picture image from https://www.pinterest.com/pin/354025220693734349/

${ }^{11}$ Acknowledge the picture image from https://www. theguardian.com/artanddesign/gallery/2015/may /22/ever-changing-seascapes-in-pictures, Acknowledge the picture image from https://www.pinterest.com/pin/354025220691815051/, Acknowledge the picture image from https://www.pinterest.com/pin/354025220691 661544/, Acknowledge the picture image from https://www.pinterest. com/pin/354025220691830434/, Acknowledge the picture image from https://www.pinterest.com/pin/354025220691918633/, Acknowledge the picture image from https://www.pinterest.com/pin/354025220691830429/, Acknowledge the picture image from http://highenoughtoseethesea.tumblr com/post/87390848056/blue-glass-photo-russell-ord, Acknowledge the picture image from https://www.pinterest.com/pin/354025220691815175/, Acknowledge the picture image from https://www.pinterest.com/ pin/354025220691815170/, Acknowledge the picture image from https://www. pinterest.com/pin/354025220691661536/, Acknowledge the picture image from https://www.pinterest.com/pin/354025220691815082/, Acknowledge the picture image from https://www.pinterest.com/pin/354025220691815124/, Acknowledge the picture image from https://www.pinterest.com pin/354025220691815123/, Acknowledge the picture image from https://www. pinterest.com/pin/354025220691815091/, Acknowledge the picture image from https://www.pinterest.com/pin/354025220691815122/, Acknowledge the picture image from https://www.pinterest.com/pin/354025220691661719/, Acknowledge the picture image from https://www.pinterest.com/ pin/354025220691661609/, Acknowledge the picture image from https://www.

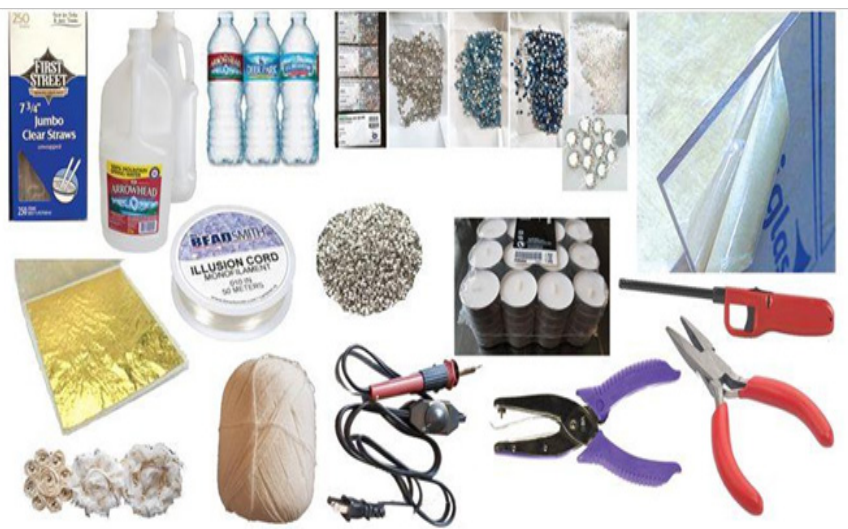

Image I 3 Raw materials and decorated materials.

\section{Materials}

The drinking straws and plastic water bottles were connected by using fishing wire, and then making the shape of a wave (Image 15). Some of the design garments were developed by using the clear polyethylene terephthalate (PETG) sheets with candles for heating and soft melting into various shapes (Image 15).

The creative upcycling avant-garde collection performed as apparel that developed two pieces of garments with reusable materials.

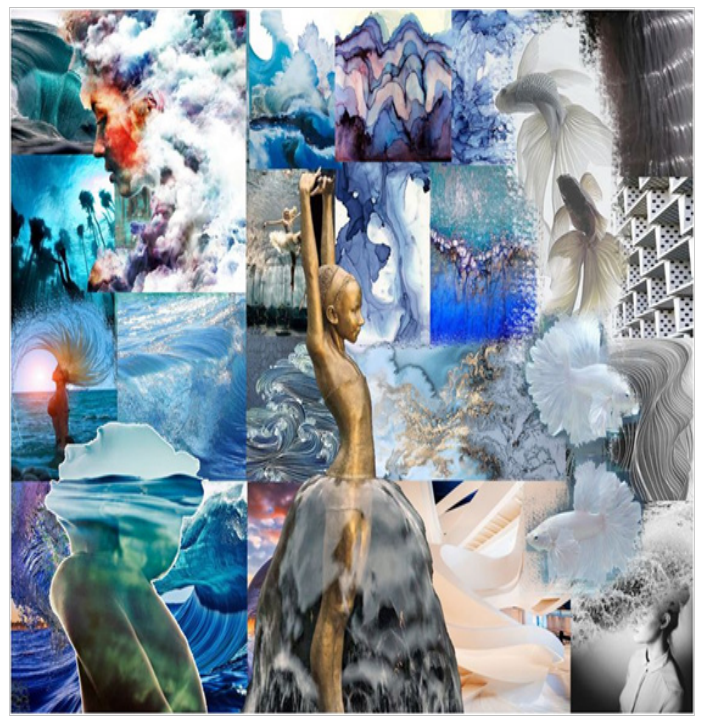

Image I 4 Collection color way and material concept board.

\section{First garment: tiered dress}

The first avant-garde garment was made from plastic drinking straws and recycled plastic water bottles with irregular circle holes. There was an inner lining dress made of tulle and lace to protect customer's skin.

Design inspiration: The first avant-garde garment symbolized the perennial problem of water shortage, and simultaneously represented pure water through the shape of strong waves. The frozen water, pinterest.com/pin/354025220691661607/, Acknowledge the picture image from https://www.pinterest.com/pin/354025220691812600/, Acknowledge the picture image from https://www.pinterest.com/pin/354025220691813016/, Acknowledge the picture image from http://lapetitemadame.tumblr.com/ post/124483094246/chasingrainbowsforever-betta-fish, Acknowledge the picture image from https://www.pinterest.com/pin/818740407227462485/ 
such as crystalline icicles, was shown as design motifs in the tiered dress. The rough waves of the sea, or scary waves like tsunamis, were represented by the wave of the skirt. The freshness and purity of the water drops falling from the sky and the sea were expressed in the dress as a motif (Image 16) $)^{12}$.

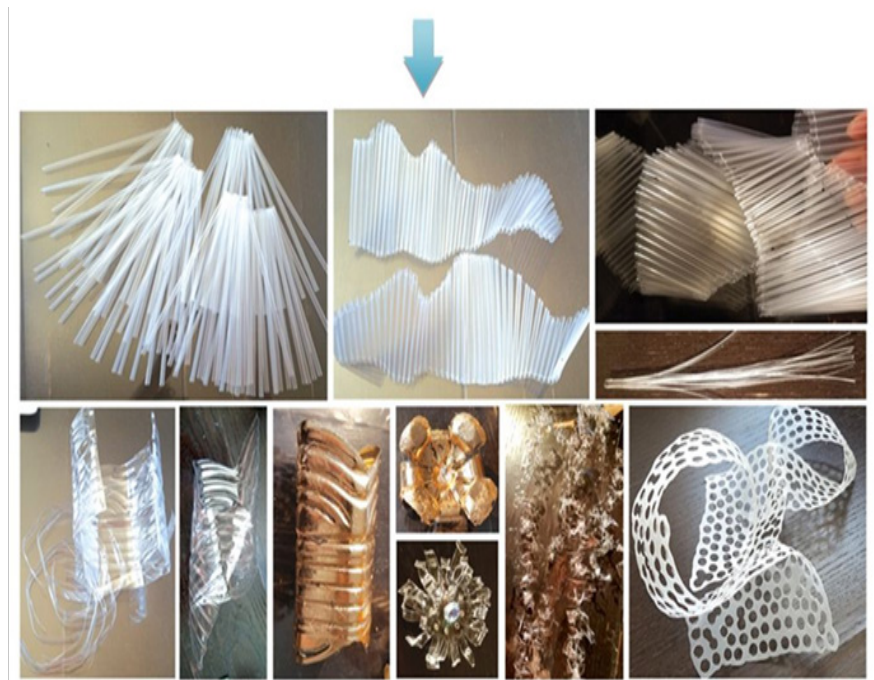

Image I 5 Developed materials from raw materials.

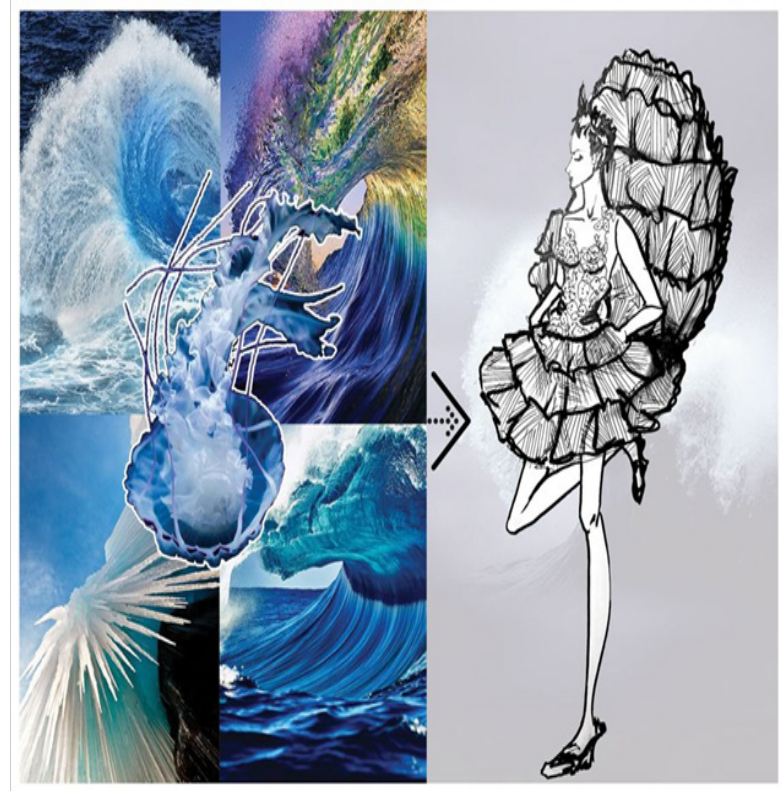

Image I 6 Tiered dress inspirations and sketch.

Raw materials: About ten thousand plastic drinking straws were used for the skirt of the tiered dress. Thirty pieces of top of the plastic water bottles were connected with fishing wire and crimp beads into the shape of a wave for the top of the dress.

Procedures of top and skirt material preparation: Tiered Dress

${ }^{12}$ Acknowledge the picture image from https://www.pinterest.com/ pin/354025220691830407/, Acknowledge the picture image from https://www. pinterest.com/pin/354025220691830434/, Acknowledge the picture image from https://500px.com/photo/2736114/untitled-by-canon-rumors?from=fav orites\%252Fkimofkims, Acknowledge the picture image from https://www. pinterest.com/pin/354025220691830425/, Acknowledge the picture image from https://www.pinterest.com/pin/354025220692227003/, Acknowledge the picture image from https:/www.pinterest.com/pin/354025220692052394/ was developed a silhouette designed at the back skirt toward the sky, which used about thirty recycled parts of one gallon high-density polyethylene (HDPE) water bottles for the top part of the dress and ten thousand clear plastic drinking straws for the skirt (Table 2).

\section{Procedures of top of the dress}

a. Thirty pieces from one-gallon water bottles sliced to four parts with scissors.

b. Holes were cut with a quarter-inch circle punch for the sliced water bottles.

c. Cleaned up the edges with scissors to express water drops created by waves.

d. Each piece of punched and trimmed water bottle was shaped by hand (Image 17).

Table 2 Materials of Tiered Dress

Materials Top of the dress $\begin{aligned} & \text { Skirt of the Closure } \\ & \text { dress }\end{aligned}$

\begin{tabular}{|c|c|c|c|}
\hline $\begin{array}{l}\text { Water- } \\
\text { related } \\
\text { Materials }\end{array}$ & $\begin{array}{l}30 \text { parts of one- } \\
\text { gallon high-density } \\
\text { polyethylene } \\
\text { (HDPE) water } \\
\text { bottles. }\end{array}$ & \multicolumn{2}{|c|}{$\begin{array}{l}10,000(250 \text { straws } \times 40 \text { boxes }) \\
\text { clear plastic } \\
\text { drinking straws: } 73 / 4 \text {-inches } \\
(19.68 \mathrm{~cm}) \times 1 / 4 \text {-inch. }\end{array}$} \\
\hline & $\begin{array}{l}\text { I 2LB strength } \\
\text { strand and } .014 \\
\text { inch thickness clear } \\
\text { fishing wire. }\end{array}$ & \multicolumn{2}{|c|}{$\begin{array}{l}\text { I } 2 \text { LB strength strand and } .014 \\
\text { inches thickness } \\
\text { clear fishing wire. }\end{array}$} \\
\hline \multirow[t]{2}{*}{$\begin{array}{l}\text { Other } \\
\text { Materials }\end{array}$} & $\begin{array}{l}2 \mathrm{~mm} \text { iron crimp } \\
\text { stopper beads. } \\
\text { I00000mAh Dual } \\
\text { USB Portable Solar } \\
\text { Battery Charger. }\end{array}$ & $\begin{array}{l}\text { Lace and Tulle } \\
\text { fabrics. }\end{array}$ & $\begin{array}{l}\text { Size three } \\
\text { and four } \\
\text { nickel-plated } \\
\text { brass snap } \\
\text { buttons. }\end{array}$ \\
\hline & $\begin{array}{l}\text { Dc } 5 v \text { to Dc I } 2 v \\
\text { Converter Step Up } \\
\text { Voltage Converter } \\
6.5 \mathrm{ft} \text { Am to } \\
\text { Dc5.52.Imm. } \\
\text { ESUMIC } 5.5 \mathrm{~mm} \\
\times 2.1 \mathrm{~mm} \mathrm{I2V} \mathrm{DC} \\
\text { Power Female Jack } \\
\text { Connector Plug } \\
\text { Adapter }\end{array}$ & $\begin{array}{l}4 \mathrm{~mm} \text { Crystal } \\
A B \text { beads. }\end{array}$ & $\begin{array}{l}0.6 \times 2.9 \times \\
3.5 \text { inches } \\
\text { nickel-plated } \\
\text { brass hooks } \\
\text { and eyes. }\end{array}$ \\
\hline
\end{tabular}

5/16- inch

crystal $A B$

hexagon beads.

$2 \mathrm{~mm}$ iron crimp stopper beads.

LEDMO 5630 Flexible Led Strip, Daylight 300pcs SMD 5630LEDs 16.4Ft DCI2VWaterproof 

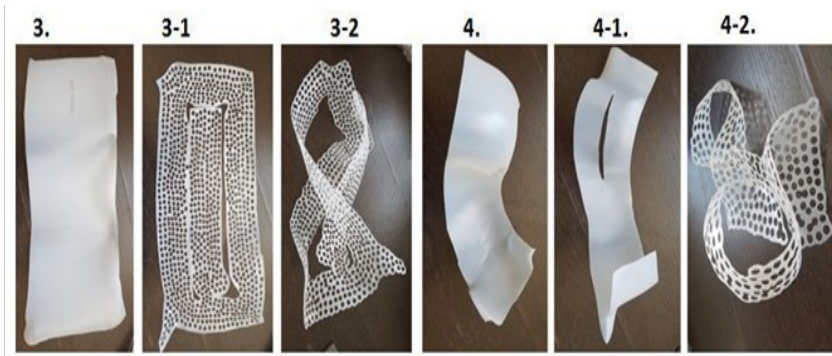

Image 17 Procedures: Shaping plastic water bottles for the top of the dress.

\section{Procedures of skirt of the dress}

i. Small holes made a $1 / 16$-inch round punch were made at both ends.

ii. Fishing wire was knotted at the end with crimp to stop bead from losing.

iii. Plastic drinking straws were pre-shaped to show the image of a wave.

iv. The plastic drinking straws were sewn with fishing wire.

v. All of the knots were tied using $2 \mathrm{~mm}$ crimp stopper beads both ends.

vi. Then drawn into a wave pattern on the tied straws.

vii. Cut with scissors and connected the other side in the same way.

viii. Twisted the connected the panels of straws for shaping.

ix. Finished using crimp stopper beads with $4 \mathrm{~mm}$ crystal beads.

x. Prepared panels of straws were connected by hand sewing to shape the skirt.

xi. The waist band was made out of woven fabric (Image 18).
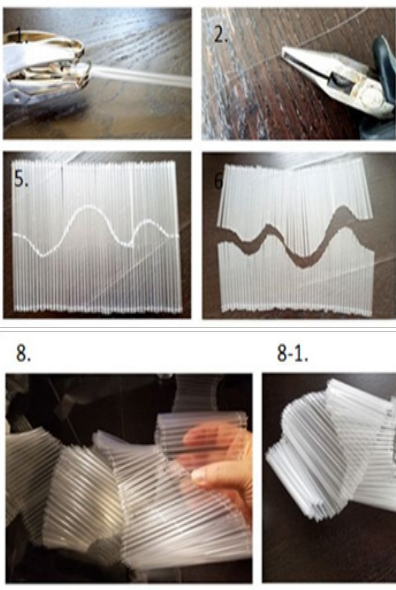

8-1.
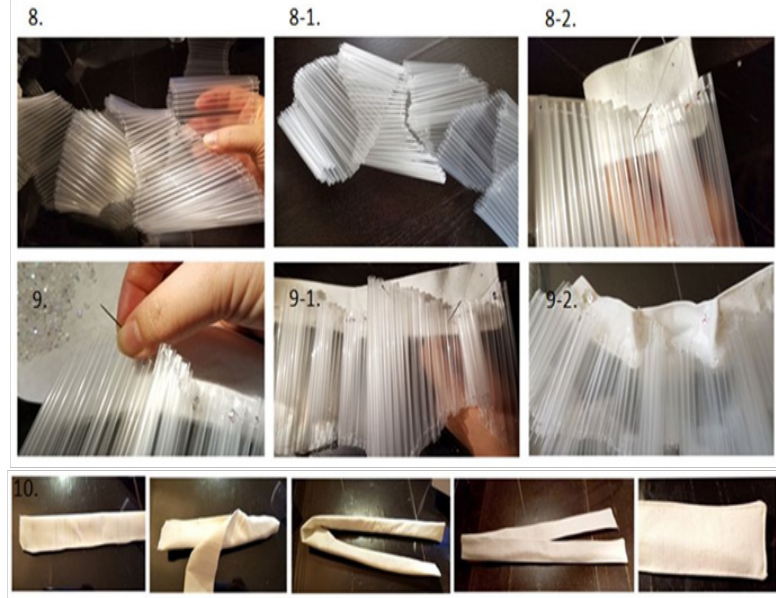

Image I 8 Procedures: Shaping plastic water bottles for the skirt of the dress.

Closure of the dress: This dress used snap buttons on the side opening. Both the top and the skirt of the dress used a side opening for closure. For the closure, the top of the dress was finished with three sets of size four nickel-plated brass snap buttons. Closure for the skirt of the dress used size three and four nickel-plated brass snap buttons and two sets of $0.6 \times 29 \times 3.5$ inches nickel-plated brass hooks and eyes (Image 19).
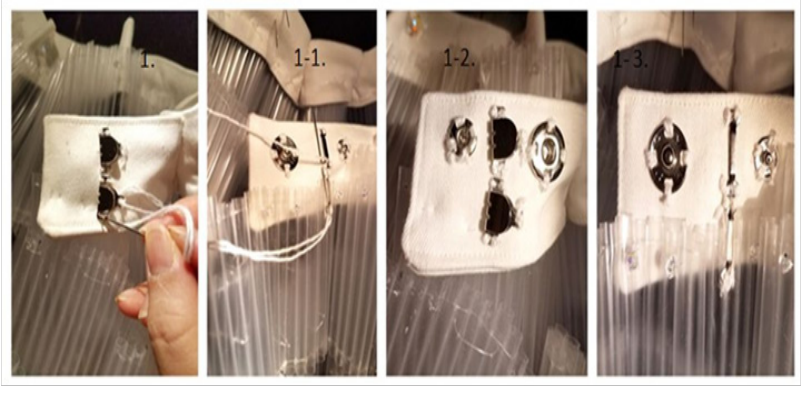

Image I 9 Procedures: Closures of tiered dress.

Developing tiered dress: Pieces of punched and trimmed water bottles were placed on the fashion body foam and connected them by hand sewing. There was an inner lining dress made of tulle and lace to protect customer's skin, with attached LED lights (Image 20).

Final pictures and illustration: The illustration and flat sketches of tiered dress were developed as follows in Image 21. The silhouette of tiered dress was developed by the raising up of the back skirt toward the sky about four or five feet (Image 22).

FEA theoretical framework: It is important to note that the, tiered dress was analyzed based on the FEA Consumer Need Model, adopting its three elements of functionality, expressiveness, and aesthetics. Focus on fit and closure ensures the perfect fit for customers, with the use of snap buttons and hook and eye closures for functional aspect. For expressive aspects, the tiered dress displays the inspiration for using recycled materials, the global water crisis. Design principles and elements were used in the emphasis of the skirt's silhouette for aesthetic value. Aesthetic and expressive aspects are the focus more so than the functional aspect here. The analysis of the tiered dress is listed on Table 3 below.

\section{Second garment: empress dress}

The empress dress used the technique of gilding gold leaf to express the loyal and noble value of both recycled garbage and plastic water bottles, and LED lights provide edge to the looks.

Design inspiration: There is a saying that "time is gold". The empress dress is inspired by the fact that water will be gold in the coming future. The aim is to express the importance of clean water in the midst of the water shortage caused by severe drought and environmental pollution all over the world (Image 23) ${ }^{13}$.

\footnotetext{
${ }^{13}$ Acknowledge the picture image from $\mathrm{https} / / \mathrm{s}-$ media-cache-ak0.pinimg.com/origina $1 \mathrm{~s} / 6 \mathrm{e} / 05 / \mathrm{eb} /$ 6 e 05 eb 36 ee 25 e 3 d 0 b 2 b 5712 d 56742 a 88 .jpg, Acknow ledge the picture image from https://www.theguar dian.com/artanddesign/gallery/2015/may/22/ever-changing-seascapes-inpictures, Acknowledge the picture image from

h t t p s : / / w w w. pinterest. c o m/ p i n / A Z Y u W X QX 2 M 7 rpU q 6 J U h F p k p W S X J M n L 5 K S B x m D H y a IB WNEok_VmQ/, Acknowledge the picture image from https://wordlesstech. com/global-warming-posters/, Acknowledge the picture image from https:// www.pinterest.com/pin/354025220691814845/,

Acknowledge the picture image from https://www.pinterest.com pin/354025220694690532/, Acknowledge the picture image from https:// www.pinterest.com/pin/354025220694690160/, Acknowledge the picture image from https://www.pinterest.com/pin/354025220692105335/, Acknowledge the picture image from https://www.pin terest.com/pin/354025220691930622/
} 

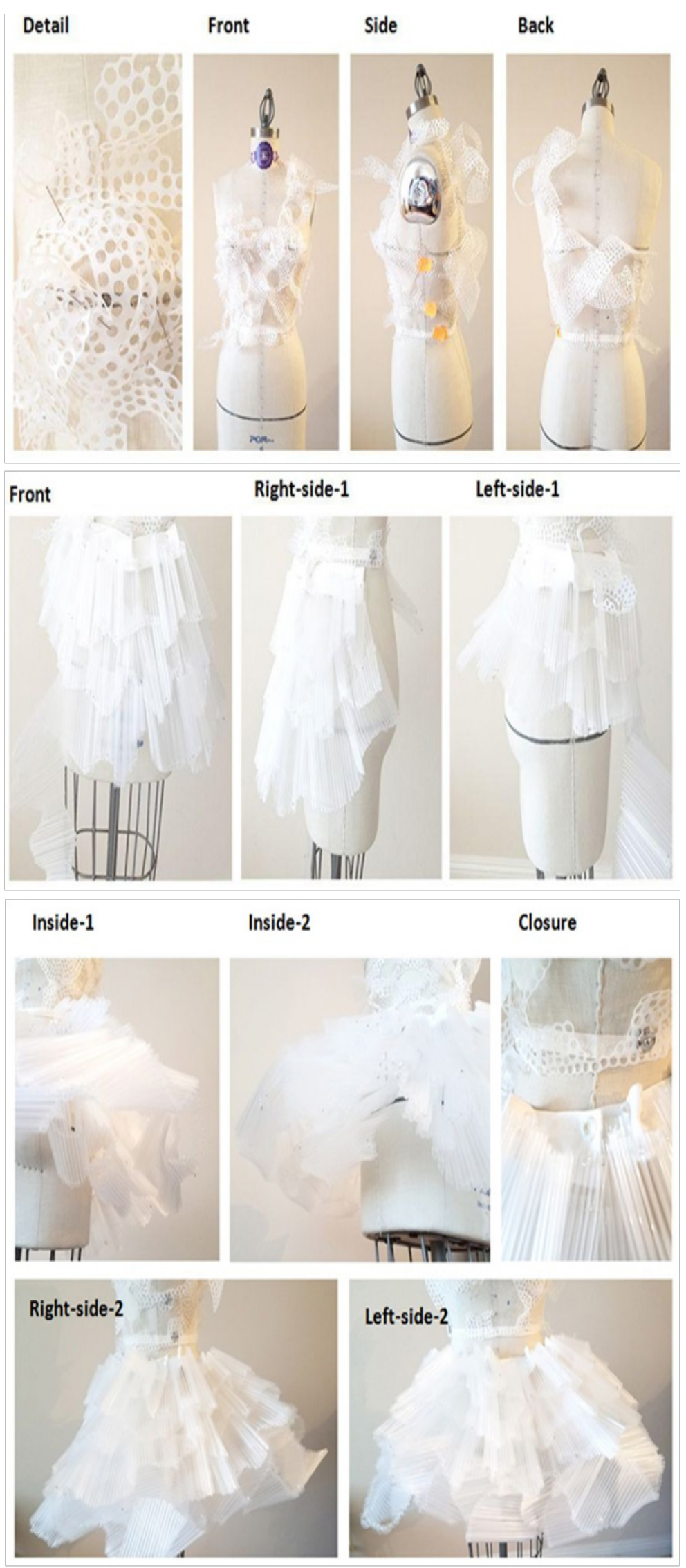

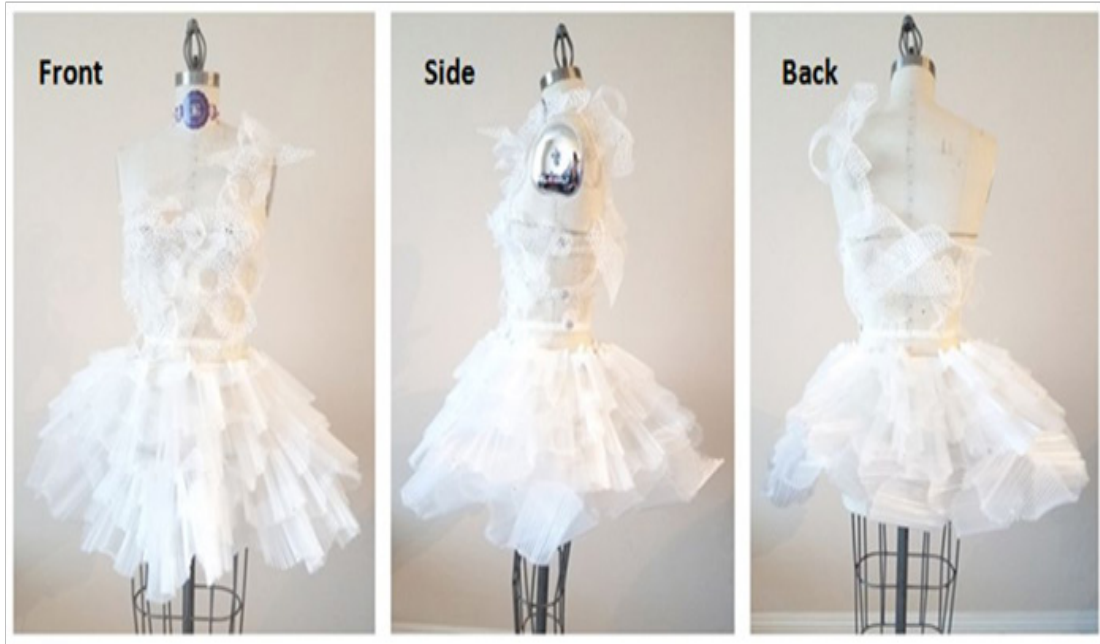

LED
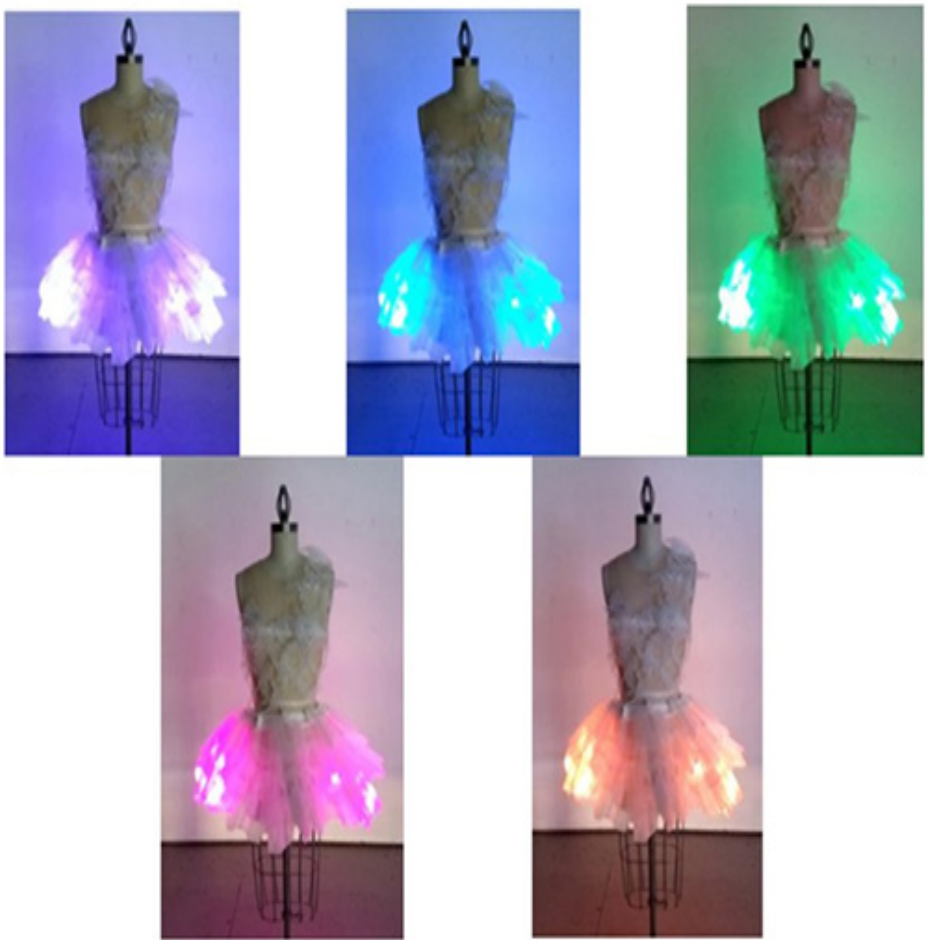

Image 20 Procedures: Pictures of the tiered dress.

Raw material: The Empress Dress was developed with recycled plated plastic water bottles. The lower part of about 160 bottles was melted with candles to create a flower shape. In addition, lots of crystal beads and hotfix stones were used as elegant decoration (Table 4).

Procedure of dress material preparation: Empress Dresses were made of two sizes of recycled water bottles, which were made into a flower shape and gold-plated with gold leaf gilding to emphasize the value of recycling.

\section{Procedures of dress}

a. Recycled one liter sized plastic water bottles were cut it into flowers.

b. Apply gilding glue to it and let it dry for about 10 seconds. c. Gilding with gold leaf. Wait about 15 seconds, and then use a brush to trim the gold plating.

d. Once the gold-plated plastic flowers are ready, decorate them with crystal beads or hotfix stones.

e. Finish the crystal beading with a crimp bead after decorating.

f. Cut the bottom of 500 milliliter-sized recycled water bottle, then twist it by hand, and then fix with crystal beads.

g. These twisted recycled water bottles were also treated with gold plating.

h. Apply gilding glue and gliding gold leaf to the edge of LED (Image 24) (Image 25). 


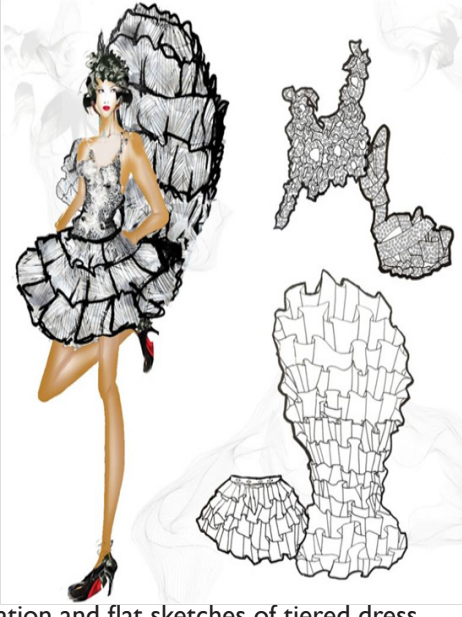

Image 2 I Illustration and flat sketches of tiered dress.
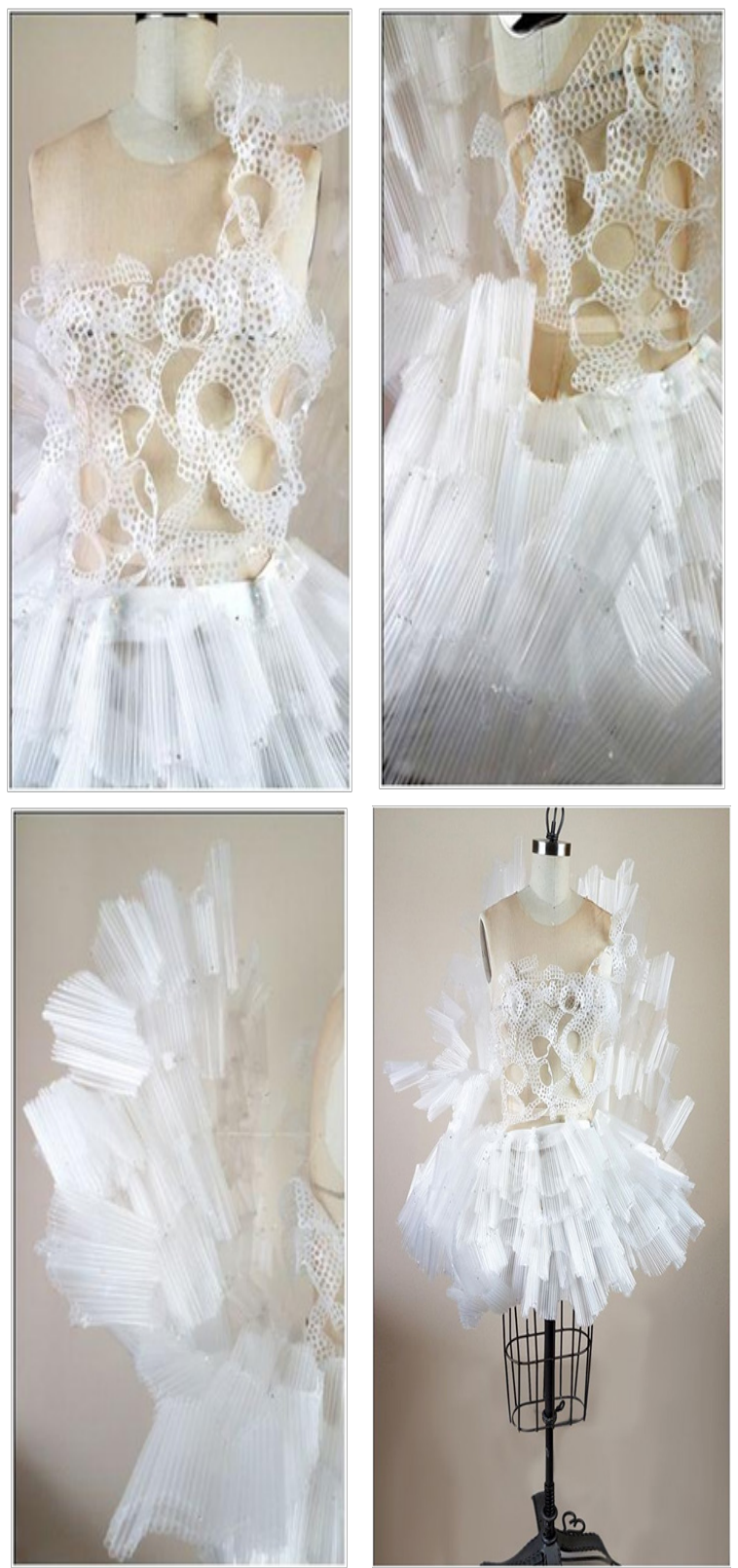

Image 22 Tiered dress.

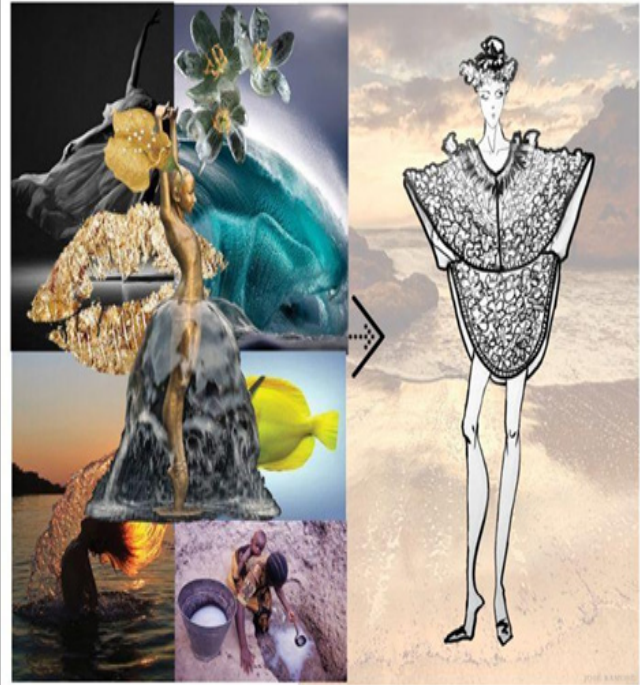

Image 23 Empress dress inspirations and sketch.

Table 3 Design Analysis of Tiered Dress

Collection reflecting plastic

material

\begin{tabular}{|c|c|c|}
\hline Functional & Expressive & Aesthetics \\
\hline $\begin{array}{l}\text { Fit / donning \& } \\
\text { doffing }\end{array}$ & values / issues & $\begin{array}{l}\text { Design principles / } \\
\text { Color }\end{array}$ \\
\hline Item [Fit] & [Values] & [Design Principles] \\
\hline $\begin{array}{l}\text { Princess style line } \\
\text { for top of the } \\
\text { dress. }\end{array}$ & $\begin{array}{l}\text { Mix influenced } \\
\text { images with related } \\
\text { materials and fabric. } \\
\text { Express the related } \\
\text { inspiration pattern } \\
\text { on top and skirt } \\
\text { part. }\end{array}$ & $\begin{array}{l}\text { Showed emphasis of } \\
\text { skirt and repetition } \\
\text { using circle wholes } \\
\text { of top. }\end{array}$ \\
\hline \multicolumn{2}{|c|}{$\begin{array}{l}\text { Widely wide of the bottom sweep. Free } \\
\text { style line into skirt part of the dress. }\end{array}$} & $\begin{array}{l}\text { Use crystal beads into } \\
\text { the waistband and } \\
\text { skirt for emphasis. }\end{array}$ \\
\hline $\begin{array}{l}\text { [Donning \& } \\
\text { Doffing] }\end{array}$ & [lssues] & [Color] \\
\hline $\begin{array}{l}\text { Side hooks and } \\
\text { eyes. }\end{array}$ & $\begin{array}{l}\text { Global water crisis } \\
\text { and environmental } \\
\text { pollution. }\end{array}$ & White. \\
\hline Side snap buttons. & Up-cycling dress. & Nude. \\
\hline $\begin{array}{l}\text { Cut edge } \\
\text { hemming of top } \\
\text { and skirt of dress. }\end{array}$ & $\begin{array}{l}\text { Plastic drinking } \\
\text { straws and recycled } \\
\text { water bottles with } \\
\text { fashion fabric }\end{array}$ & Clear. \\
\hline $\begin{array}{l}\text { No edge finishing a } \\
\text { straw edge. }\end{array}$ & ne end of plastic & \\
\hline
\end{tabular}

Closure of the dress: For a closure, the empress dress was opened in the center front of the dress. Ten sets of size four nickel-plated brass snap buttons were used for an effective way of finishing. All of snap buttons were attached using fishing wire by hand sewing (Image 26).

Developing empress dress: When all the materials are ready, make dress patterns, and then cut the PET panel using paper patterns, and draw a pattern on it to make gold. Gold plate the LED light in both 
virtual places and attach using the fishing line and the crimp bead at the end. Gold-plated LED light and flower-shaped recycled water bottles were placed on both sides of the virtual spot on the prepared PET panel. Attach all prepared recycled water bottle flower shapes to the main dress using a fishing line and crimp bead. Sew the inner lining dress with a lace and tulle cloth using a pattern, and sew with a sewing machine (Image 26).

Final pictures and illustration: The illustration and flat sketches of the empress dress were developed as follows on Image 27. To emphasize the importance of the water crisis, the dresses were feature gold color, emphasized by the use of LED light to express the importance of further utilization of recycled water bottles (Image 28).
FEA theoretical framework: Design analysis of the empress dress adopted the three elements of functionality, expressiveness, and aesthetics. Inner lining dress was focused on fit and closures were used to fit the body of the customer using a zipper and main dress used several snap buttons as closure for a functional aspect. For expressive aspects, the empress dress was represents the related water shortage and environmental issues as inspiration for using recycled plastic material. Aesthetically, this dress uses design principles by emphasizing the use of gold color and crystal beading, and balance, repetition and rhythm have been used as a design element by the stacking of recycled water bottles in various shapes. Aesthetic and expressive aspects were the focus rather than a functional aspect here. The analysis of the empress dress is listed on Table 5 below.
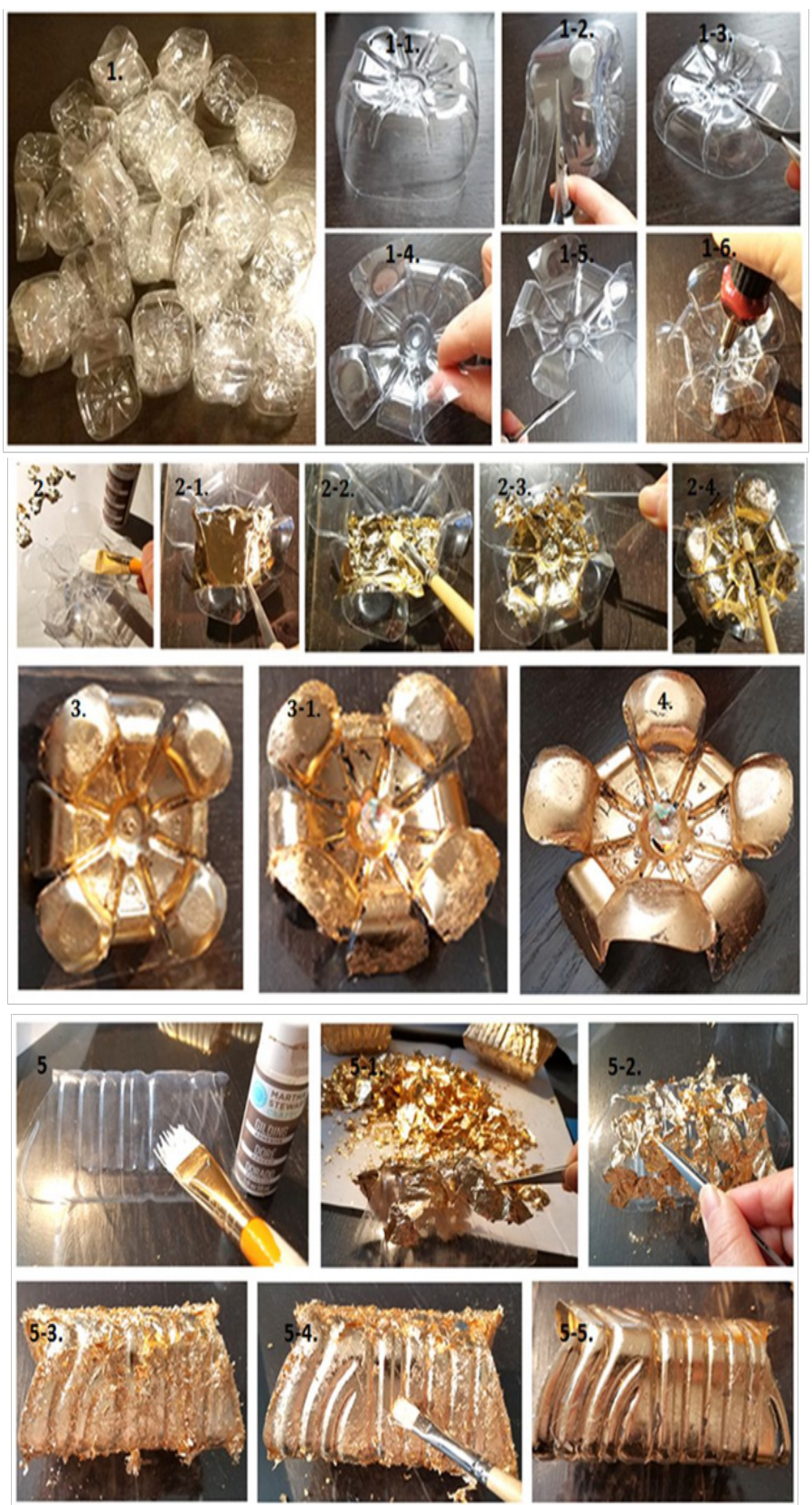

Image 24 Procedures: Plastic drinking bottles and detail photo. 


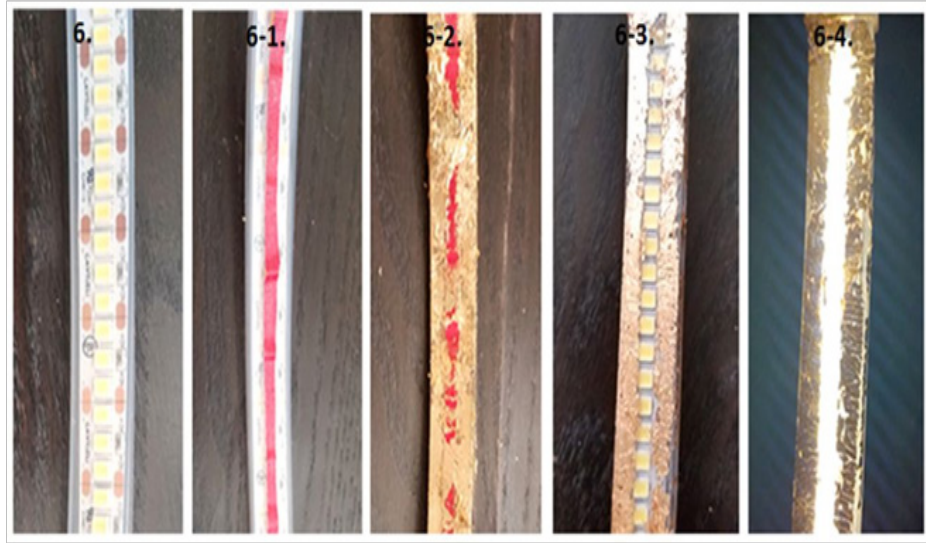

Image 25 Procedures: LED light.
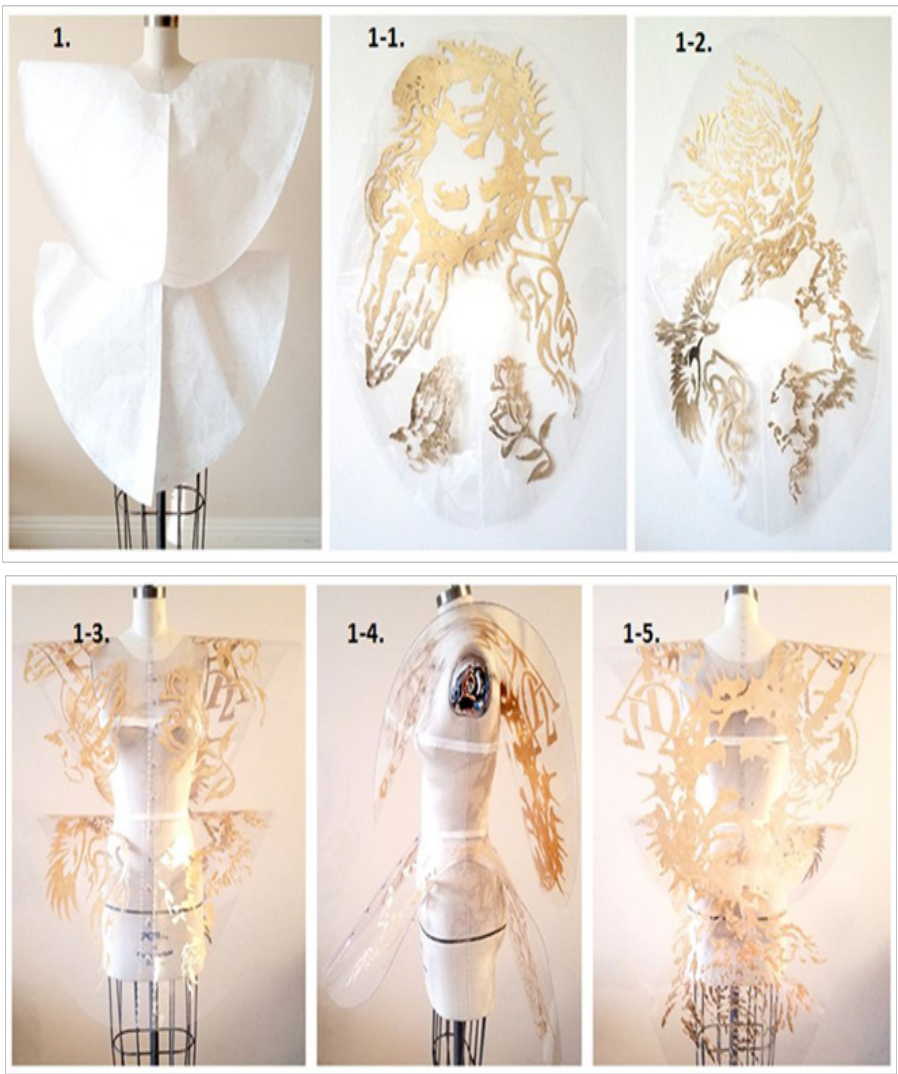

$1-5$.
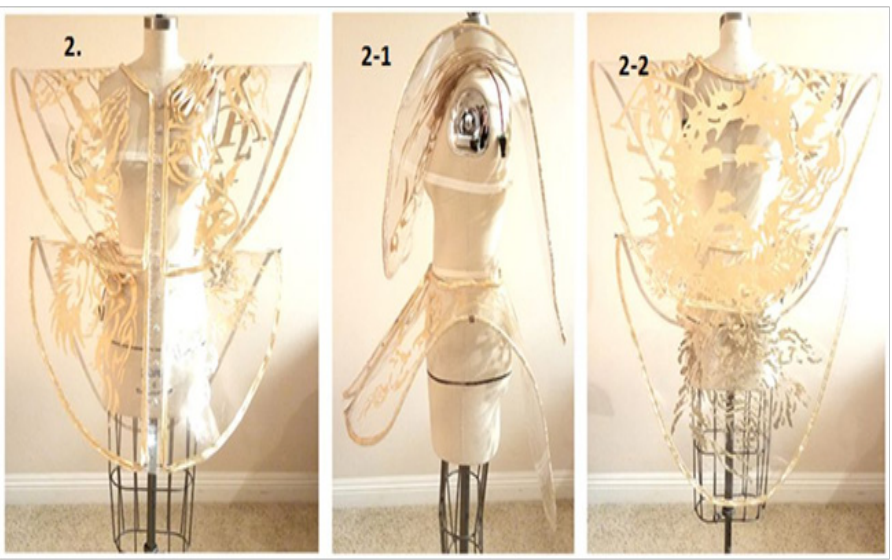

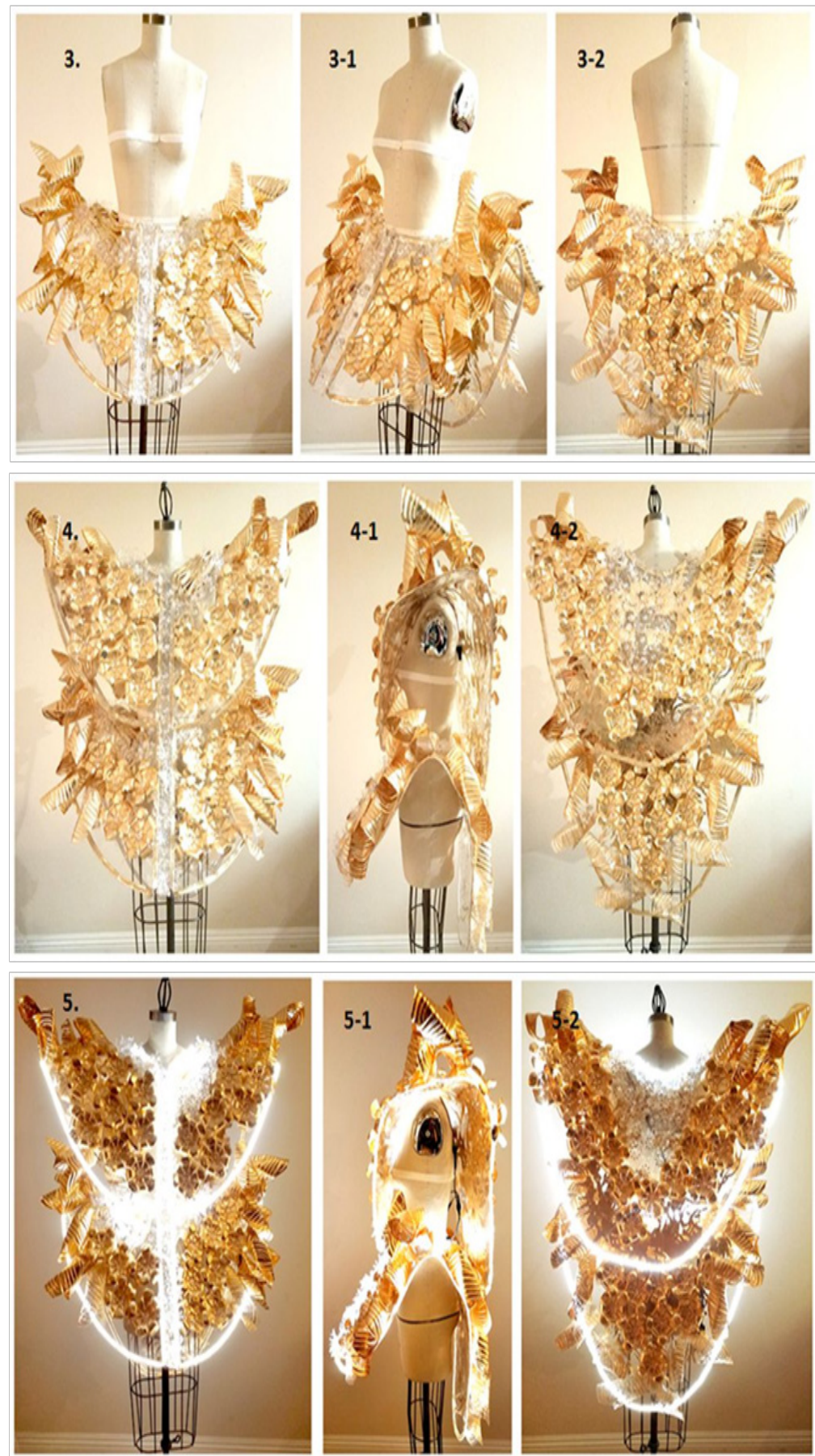

Image 26 Procedures: Empress dress.

Table 4 Materials of Empress Dress

\begin{tabular}{lll}
\hline Materials & Dress & Closure \\
\hline $\begin{array}{l}\text { Water-related } \\
\text { Materials }\end{array}$ & 80 pieces of 500-milliliter polyethylene terephthalate (PET) water bottles. \\
& 75 pieces of one -liter polyethylene terephthalate (PET) water bottles. \\
& $\begin{array}{l}\text { 8-feet } \times \text { 6-feet } \times \text { 0.0I-feet polyethylene terephthalate with the addition of } \\
\text { glycol (PETG). } \\
\text { I2LB strength strand and .014-inch thickness clear fishing wire. }\end{array}$
\end{tabular}


Table Continued.

\begin{tabular}{|c|c|c|}
\hline Materials & Dress & Closure \\
\hline \multirow[t]{9}{*}{ Other Materials } & Lace and Tulle fabrics. & $\begin{array}{l}\text { Size three and ten nickel-plated brass snap } \\
\text { buttons. }\end{array}$ \\
\hline & Gliding gold leaf. & Metal O-rings. \\
\hline & \multicolumn{2}{|l|}{$2 \mathrm{~mm}$ iron crimp stopper beads. } \\
\hline & \multicolumn{2}{|l|}{$4 \mathrm{~mm}$ crystal $A B$ beads with silver foil. } \\
\hline & \multicolumn{2}{|l|}{$4 \mathrm{~mm}$ clear crystal hotfix stones. } \\
\hline & \multicolumn{2}{|l|}{ 5/16- inch crystal AB hexagon beads. } \\
\hline & \multicolumn{2}{|l|}{$\begin{array}{l}\text { LEDMO } 5630 \text { flexible LED strip, daylight 300pcs SMD 5630LEDs I6.4Ft } \\
\text { DCI } 2 \text { V waterproof. }\end{array}$} \\
\hline & \multicolumn{2}{|l|}{$100000 \mathrm{mAh}$ Dual USB portable solar battery charger. } \\
\hline & \multicolumn{2}{|l|}{ Dc $5 v$ to $D c 12 v$ converter steps up voltage converter $6.5 \mathrm{ft}$ to Dc5.52. Imm. } \\
\hline
\end{tabular}

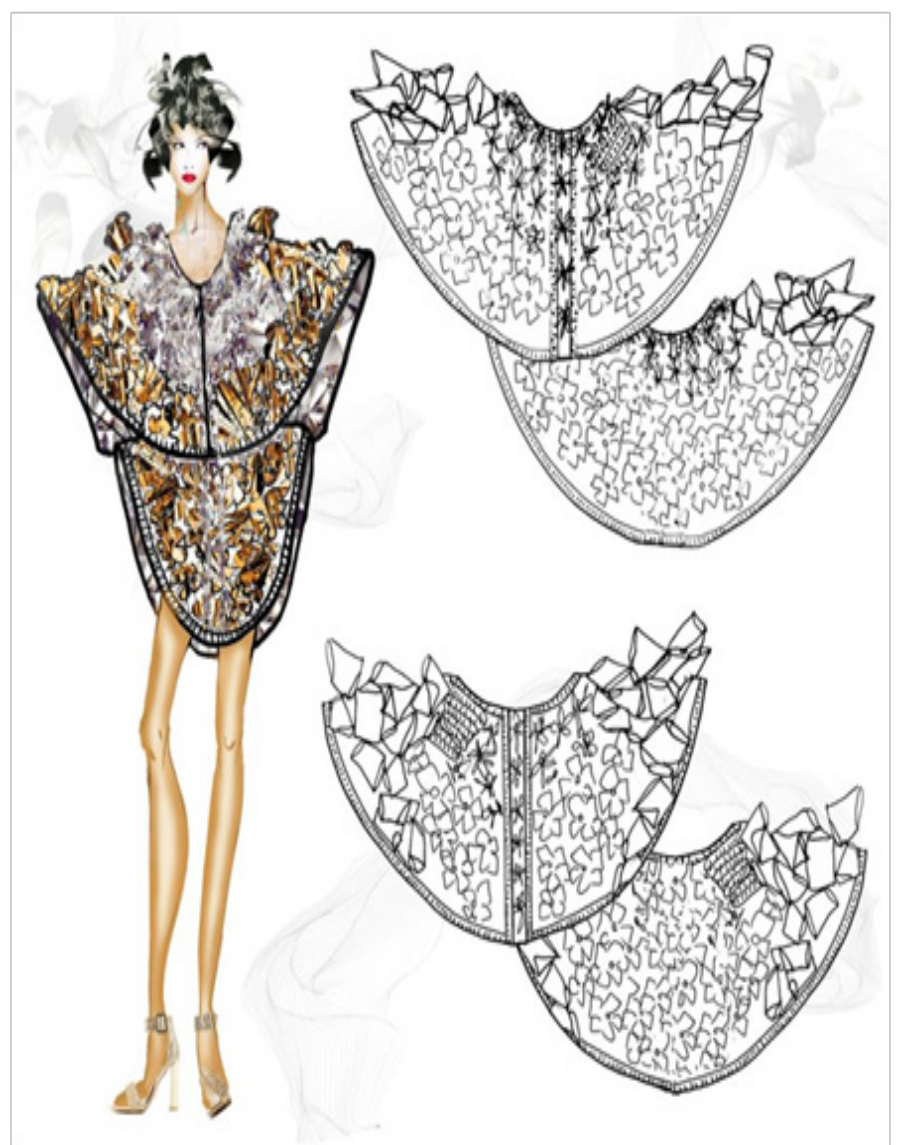

Image $\mathbf{2 7}$ Illustration and flat sketches of empress dress. 
Table 5 Design Analysis of Empress Dress

\section{Collection reflecting plastic material}

\begin{tabular}{|c|c|c|}
\hline Functional & Expressive & Aesthetics \\
\hline Fit / donning \& doffing & values / Issues & Design principles / Color \\
\hline Item [Fit] & [Values] & [Style] \\
\hline \multirow[t]{4}{*}{$\begin{array}{l}\text { Inner dress using princess style line } \\
\text { for fitting }\end{array}$} & $\begin{array}{l}\text { Mix influenced environmental pollution plastic } \\
\text { materials and fabric. Express the related inspiration } \\
\text { pattern on the top part for using plastic water } \\
\text { bottles }\end{array}$ & Showed emphasis, and balance. \\
\hline & & $\begin{array}{l}\text { Clear recycled water bottles on the flower } \\
\text { shaped pattern for meaningful images. }\end{array}$ \\
\hline & & The effect of shinny crystal beads. \\
\hline & & $\begin{array}{l}\text { Decorated recycled water bottles with } \\
\text { flower shapes on the top and skirt part }\end{array}$ \\
\hline [Donning \& doffing] & [lssues] & [Color] \\
\hline $\begin{array}{l}\text { Center front opening using snap } \\
\text { buttons. }\end{array}$ & Global water crisis. & Clear \\
\hline $\begin{array}{l}\text { Finishing each fishing wire using } \\
\text { crimp beads. }\end{array}$ & Up-cycling materials. & White \\
\hline \multirow[t]{2}{*}{ Side zipper for inner dress } & Reduce the disposable plastic usage. & Nude \\
\hline & Protect the Environmental pollution and water & Gold \\
\hline
\end{tabular}

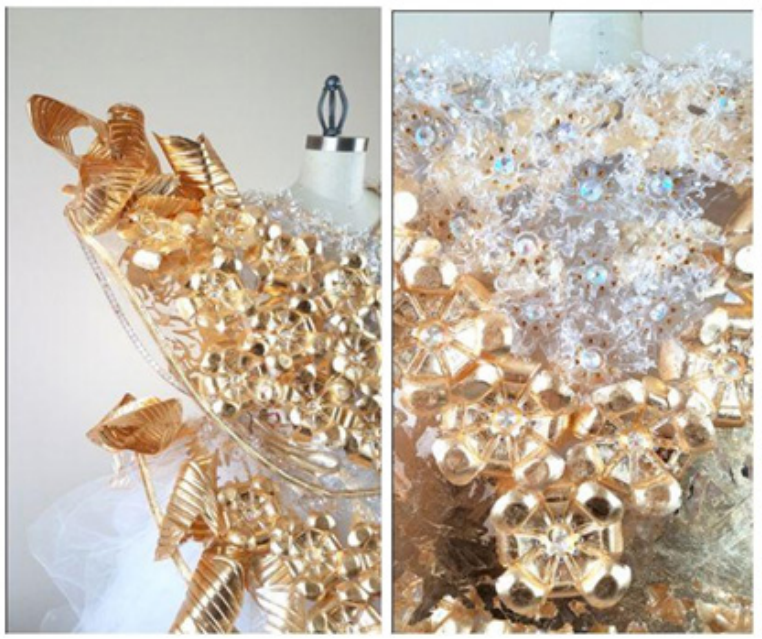

Image 28 Empress Dress.

\section{Conclusion}

The purpose of this study was to develop an avant-garde clothing collection using recycled water-related materials, and it showed the possibility to create elaborate and beautiful avant-garde collections using waste materials. Using the FEA Consumer Needs Model, this chapter proved to be successful. The collection showed apparel designers and fashion industry professionals to express and create beauty of clothing with discarded materials or non-apparel materials. There were some problems connecting plastic materials. Various super
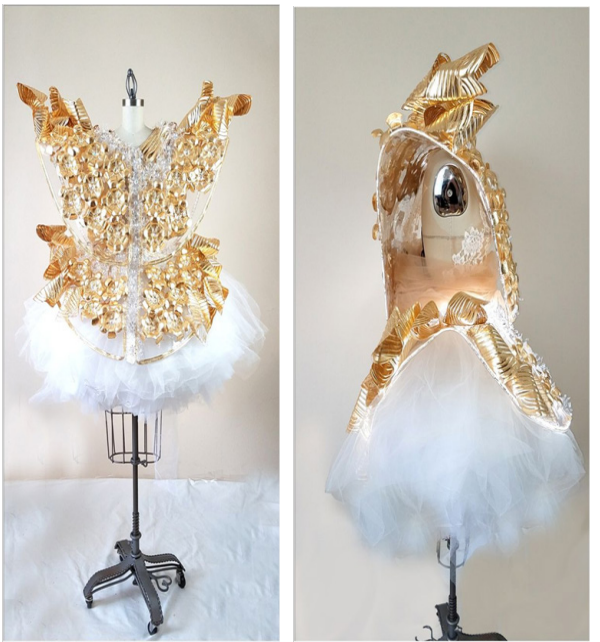

glues materials like E6000 glue, or special tape were not effective due to the properties of the plastic used. As a result of multiple repetition, investigations, and experimentation, it was discovered that melting the plastics themselves using the heat of a candle enabled materials to be adhered. In addition, the use of fishing line and crimp beads allowed materials to be strongly bonded.

Through this chapter, which provides the actual method of construction, readers will be able to recycle garbage in the house and make a simple work to contribute to the reduction of the global 
environmental pollution problem. Furthermore, seeing that this collection can be shown by public and that the garbage can be expressed as a beautiful art work, it will attract the attention of consumers, change their consciousness, and conserve limited resources.

The contributions of the current chapter were twofold, with relation to academics and the fashion industry. For the academic contribution, this study has shown how practical research can be connected to theoretical analysis through the consideration given to each dress in the collection. Second, an industrial contribution is made by creating aesthetic recycled dresses out of used water bottles. The dresses were created through a unique and innovative process that manipulated non-fabric materials into strong and wearable garments incorporating fishing wire and clips, a process unseen until this research. This research chapter provided an example of how nontextile materials and even discarded materials can be used to craft current designs. For example, after the fashion show the designs were praised by investors of design houses such as Chanel and Dolce and Gabbana as well as retailers such as Bloomingdale's and Hudson Bay Company. Through the avant-garde collection, fashion designers, fashion industry professionals, and consumers will do their part to show our respect and love for the environment through small scale recycling to a change in the consciousness of consumers' recycling.

The avant-garde collection developed will contribute to consumer awareness pollution, also provides an example showing fashion designers and fashion industry professionals such as manufacturers, merchandisers, retailers, fashion design students, and fashion educators guide them how to express beauty using sustainable, nongarment materials such as plastic water bottles and straws. Moreover, consumer awareness of clothing and fashion in the long term could contribute to increased sustainability in the fashion industry for developing not only garments but also a variety of artistic lifestyle products.

Furthermore, this collection can contribute to an increase in the number of merchandise-seekers who are pursuing a sustainable lifestyle without environmental degradation, thus reducing the world's enormous environmental impact through the recycling of plastic water bottles by activating the consumer's conceptual and conscious awareness.

\section{Limitations and research implications}

This chapter has certain limitations. When the dresses were made, some parts of the plastic materials were broken while making dresses because the plastic was hard. The dresses were repaired when this happened. Moreover, due to the bulky size of the art work, it was not easy to carry and store them. However, it can be seen that recycled plastic bottles prove to be a good model as recycled art work if consumers use it for small accessories or light fixtures.

The research focused on reusing a variety of recyclable materials, including recyclable water-related materials such as polyethylene terephthalate (PET), high-density polyethylene (HDPE), and plastic drinking straws. The future research will explore a collection of plastic materials with more advanced sustainability, as well as rubber, paper, water caps, plastic bags, and discarded clothes.

\section{Acknowledgements}

None.

\section{Conflict of interest}

Author declares that there is no conflict of interest.

\section{References}

1. Lamb JM, Kallal MJ. A conceptual framework for apparel design. Clothing \& Textiles Research J. 1992;10(2):42-46.

2. Kim J, Shirdel S, Pontikis K. Sustainability fashion practices: Women's apparel in the U.S. industry. The International Journal of Environmental, Cultural, Economic \& Social Sustainability. 2011;7(4):115-134.

3. McCormick J. The global environmental movement. London: Wiley; 1995. p. 312.

4. Winge TM. Green is the new black: Celebrity chic and the 'Green' commodity fetish. Fashion Theory: J Dress, Body \& Culture. 2008;12(4):511-523.

5. Municipal Solid Waste. Wastes - Non-Hazardous waste-Municipal solid waste. United States Environmental Protection Agency. 2014

6. Our Common Future, Chapter 2: Towards Sustainable Development UN Documents: Gathering a Body of Global Agreements. 2017.

7. Molinaro H. Plastic water bottles go to waste, says Calif. conservation agency. Plastics Engineering. 2003;59(7):64.

8. Bottled Water Facts. Ban the Bottle.

9. Chua P. Plastic water bottles are toxic to ecology. Filipino Reporter. 2016;44(24):33.

10. Claudio L. Waste couture: Environmental impact of the clothing industry. Environ Health Perspect. 2007;115(9):A448-A454.

11. Thomas S. From 'green blur' to ecofashion: Fashioning an eco-lexicon. Fashion Theory: J Dress, Body \& Culture. 2008;12(4):525-539.

12. Avant-garde art. Encyclopedia of Art Education.

13. Avant-garde. Merriam Webster Online.

14. Adamson W. How avant-gardes end-and begin: Italian futurism in historical perspective. New Literary History. 2010;41(4):855-874.

15. Crane D. Fashion design and social change: Women designers and stylistic innovation. J American Culture. 1999;22(1):61-68.

16. Cholachatpinyo A, Fletcher B, Padgett I, et al. A conceptual model of the fashion process - part 1.J Fashion Marketing \& Management. 2002;6(1):11-23.

17. Tsunamis. Department of Homeland Security.

18. Emma R. How do tsunamis affect human lives? Sciencing. 2017.

19. Ostrow R. The Fairchild Dictionary of Retailing. Oxford, New York: Fairchild; 2008. p. 480.

20. Ecos C. LED lighting technologies and potential for near-term applications. Ecos Consulting. 2003. p. 1-89.

21. Waste Recycling. Ecoca.

22. Amber M. What is eco art? Plushbeds. 2016.

23. Peter L. Aesthetics and pleasure, art and beauty. 2008.

24. Waste Classification Definitions. California Environmental Protection Agency. 2006.

25. Robert K, Thomas P, Anthony L. What is sustainable development? Environment: Science and Policy for Sustainable Development. 2005;47(3):8-21. 
26. Clough W, Jean-Lou C, Carol C. Sustainability and the University. The Presidency. 2006.

27. Bottled Water Facts. Ban the Bottle.

28. Manzoor KP. The global water crisis: Issues and solutions. IUP J Infrastructure. 2011;9(2):34-43

29. The plastic water bottle effect. One Green Planet. 2013.

30. Schmacher EF. Small in beautiful: Economics as if people mattered: 25 years later with commentaries. London: Hartley and Marks Publishers; 1999. p. 286.

31. Crabbe A. Three strategies for sustainable design in the developing wor1d. Design Issues. 2012;28(2):6-15.

32. McDonough W, Braungart M. Cradle to cradle - Remaking the way we make things. New York: North Point Press; 2002. p. 208.

33. Parija K. The company turning 4 billion plastic bottles into clothes. CNN Tech. 2016.
34. Lytle C. When the mermaids cry: The great plastic tide. Plastic Pollution Organization. 2017.

35. Solutions to Plastic Pollution in our Oceans. Natural Resources Defense Council.

36. Jasmin C. Pauline van Dongen's "Solar Shirt" is a chic phone charger you wear. Ecouterre. 2015

37. Lulu C. LED clothing may be the next big fashion statement. Digital Trends. 2015

38. Samata A. Sustainable fashion needs to be design-led. The Guarian. 2013

39. Flexible LED technology may complement flexible solar thin film clothing. Tek-Think. 2016.

40. Ady F. 22 Flashy LED fashion pieces. Trend Hunter Tech. 2015.

41. Lori Z. "Back to the Future" Inspires self-charging textiles, clothing. Ecouterre. 2016 


\section{Appendix A}

\section{Avant-Garde Clothing Collection Images}
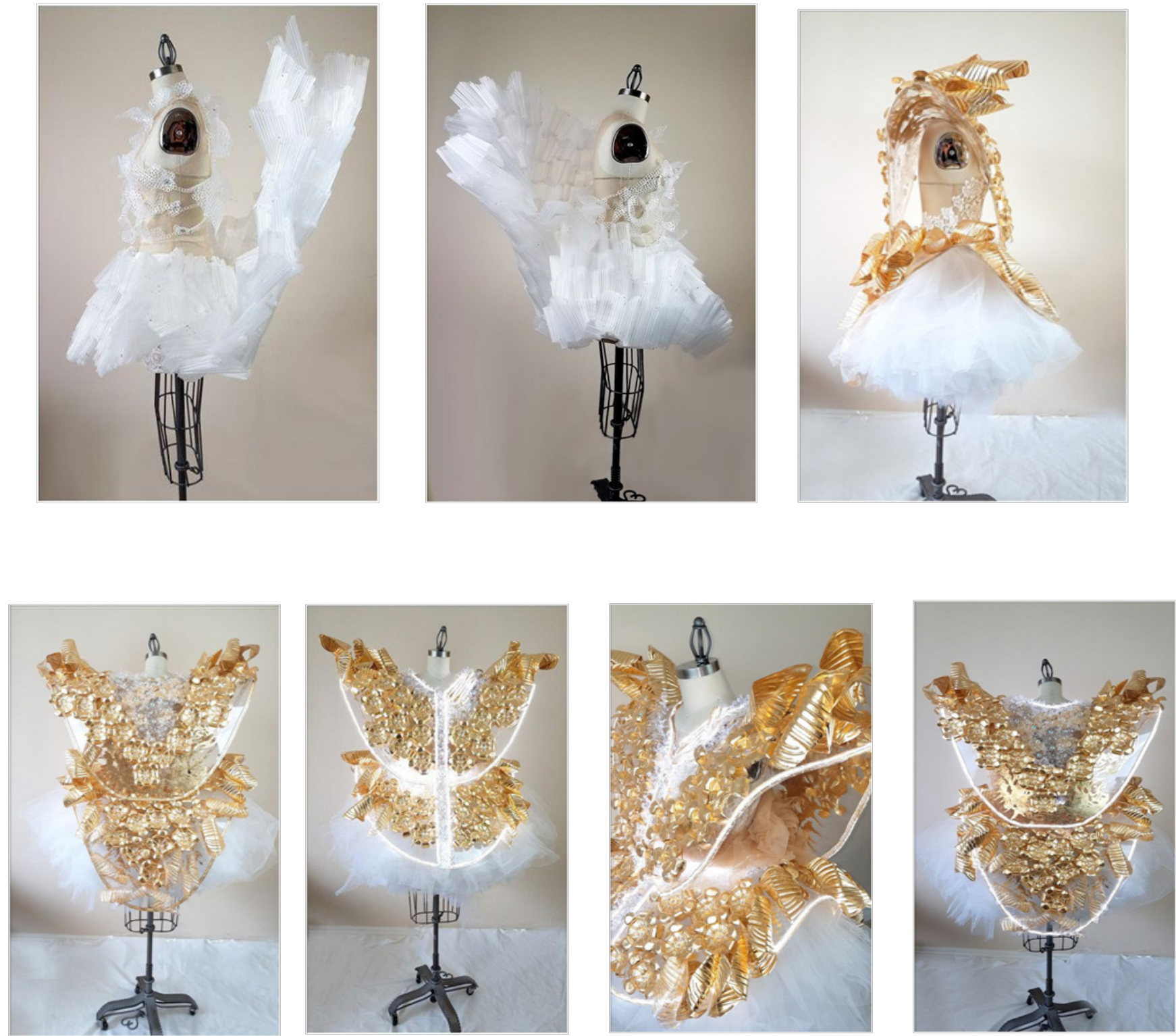


\section{Appendix B}

I. The $38^{\text {th }}$ Annual Trends Fashion Show at California State University, Northridge.
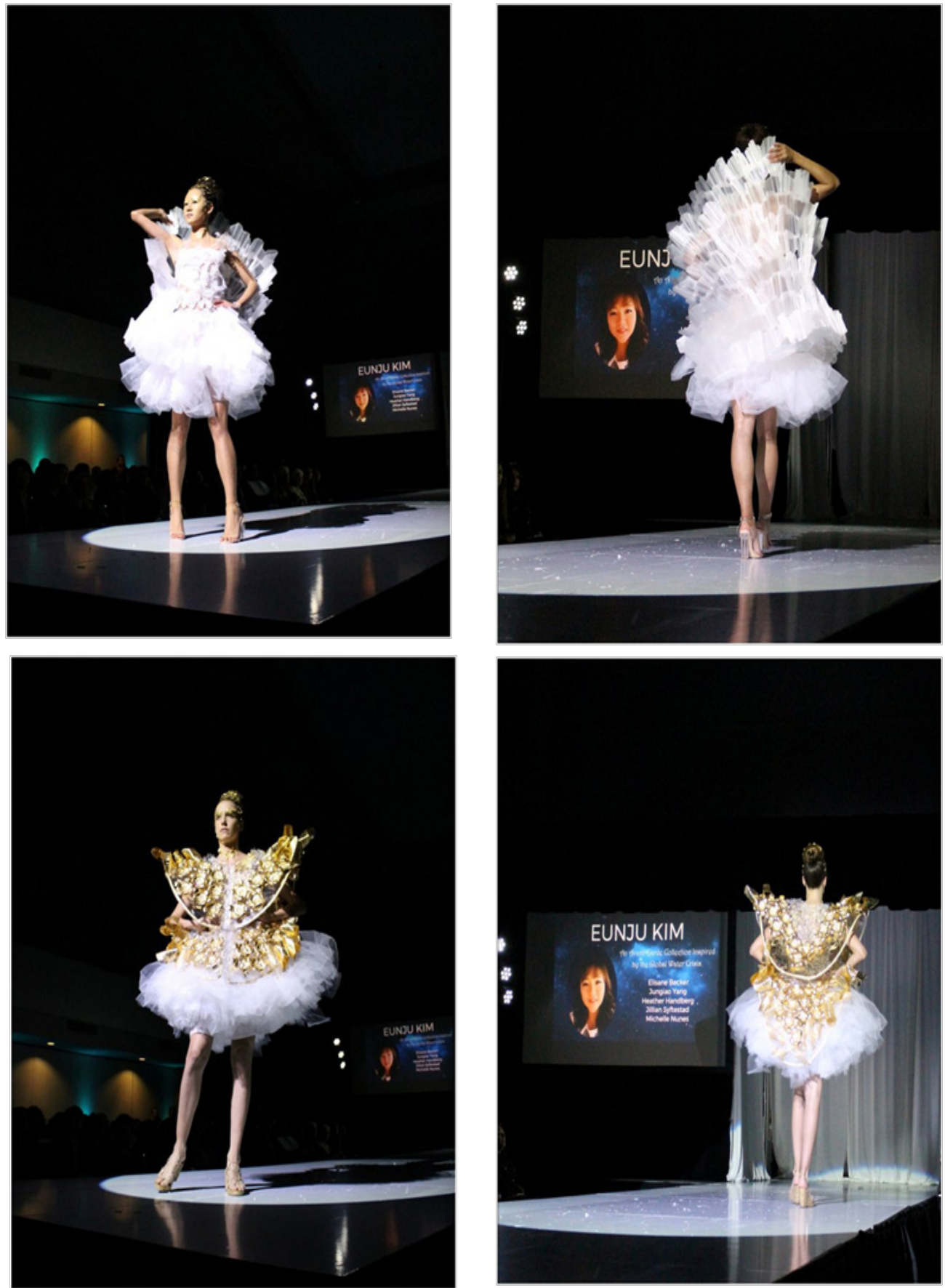